\title{
Nanoparticles for multimodal in vivo imaging in nanomedicine
}

\author{
This article was published in the following Dove Press journal: \\ International Journal of Nanomedicine \\ 29 January 2014 \\ Number of times this article has been viewed
}

\author{
Jaehong Key ${ }^{1-3}$ \\ James F Leary ${ }^{1-4}$ \\ 'Weldon School of Biomedical \\ Engineering, ${ }^{2}$ Birck Nanotechnology \\ Center, ${ }^{3}$ Bindley Bioscience Center, \\ ${ }^{4}$ College of Veterinary Medicine, \\ Purdue University, West Lafayette, \\ IN, USA
}

\begin{abstract}
While nanoparticles are usually designed for targeted drug delivery, they can also simultaneously provide diagnostic information by a variety of in vivo imaging methods. These diagnostic capabilities make use of specific properties of nanoparticle core materials. Nearinfrared fluorescent probes provide optical detection of cells targeted by real-time nanoparticledistribution studies within the organ compartments of live, anesthetized animals. By combining different imaging modalities, we can start with deep-body imaging by magnetic resonance imaging or computed tomography, and by using optical imaging, get down to the resolution required for real-time fluorescence-guided surgery.
\end{abstract}

Keywords: nanomedicine, nanoparticles, multimodal imaging, CT, MRI, NIRF, PET, cancer

\section{Introduction}

In vivo imaging has made enormous strides in the past 40 years. Many of these advances have occurred due to the rapid growth of computing power that has enabled computed tomography (CT) of X-rays, magnetic resonance imaging (MRI), and positron emission tomography (PET). All of these imaging modalities provide different information about the patient. CT scans provide information about structure and are most sensitive to electron-dense elements, such as those found in bones. MRI scans provide information about soft tissues, and are most sensitive to tissues and organs. PET scans can provide information about metabolic parameters, and can be particularly sensitive to detection of high-metabolism tumors and infections. The resolution of both CT and MRI scans can be significantly improved by introduction of contrast agents that further increase the electron density in the former or the relaxation time in the latter. While in vivo optical imaging has been of limited use in humans, it can be combined with MRI or PET and can be used for fluorescence-guided surgery. ${ }^{1}$ Multicomponent nanoparticles (NPs) can contain two or more imaging contrast agents that permit several imaging techniques to be used. More importantly, NPs of appropriate composition can greatly improve the resolution of each of these imaging modalities. In this paper, we review each of these imaging modalities separately and then together in appropriate combinations for "multimodal imaging".

Nanomedicine provides an exciting new paradigm shift for medicine, and may have a huge impact on health care. Part of that paradigm shift is provided by the targeted delivery of new and conventional drugs at much lower doses, due to a combination of molecular targeting and increased circulation time. Another part of the paradigm shift is the blending of therapeutics and diagnostics into a simultaneous "theranostics".
Correspondence: James F Leary Birck Nanotechnology Center, Discovery Park, Purdue University, 1205 West State Street, West Lafayette, IN 47907, USA

Tel +l 7654947280

Fax +I 7654966443

Email jfleary@purdue.edu 
Complex nanomedical systems can be designed and constructed to contain drugs or gene therapy, and simultaneously provide high-resolution three-dimensional (3-D) multimodal imaging of diseased cells in the body for very early detection of diseases. ${ }^{2}$

\section{Review/overview of medical imaging}

This section will briefly introduce about four imaging modalities (MRI, CT, PET, and fluorescent optical imaging). These imaging modalities can help us visualize in vivo systems, and can provide anatomical, physiological, or molecular information on the systems. The sensitivity or specificity of the information by the imaging modality can be much improved by exogenous imaging contrast agents, while a single imaging modality still has its limitations with respect to spatial resolution, sensitivity, or tissue-penetration depth. In this section, basic principles, contrast agents, and features of each imaging modality will be covered. Table 1 summarizes and compares each feature of these imaging modalities.

\section{Magnetic resonance imaging}

MRI is a noninvasive imaging modality that is able to provide various information on the inside of the body, including anatomical, physiological, and even molecular information. MRI offers high contrast of soft tissues and enough penetration depth to visualize the entire human body. Depending on the power of the magnetic field, high spatial resolution of 10-100 $\mu \mathrm{m}$ can be acquired. However, spatial resolution for human body imaging is generally restricted to approximately $1 \mathrm{~mm}$ at current US Food and Drug Administration (FDA)-approved (3-Tesla) magnetic field strengths. While the 3-Tesla MRI machines can still provide detailed anatomical information, images for molecular information are very limited, due to their low sensitivity. Therefore, in order to improve the low sensitivity of MRI, various exogenous MRI contrast agents (eg, iron oxide [IO], gadolinium [Gd]) have been applied and are being further developed.

\section{Principles of MRI and contrast agents}

MRI produces contrast in biological systems by measuring the relaxation processes of hydrogen protons in different microenvironments. When hydrogen protons are exposed in an external magnetic field $\left(\mathrm{B}_{0}\right)$, a small portion of the proton nuclei aligns in the $\mathrm{B}_{0}$ direction, and the nuclei rotate or precess gyroscopically $(\gamma)$, with a net magnetic moment $(\mathrm{m})$ and a Larmor frequency $\left(\omega_{0}=\gamma \mathrm{B}_{0}\right)$. When a resonant radio frequency $(\mathrm{RF})$ as a second magnetic field $\left(\mathrm{B}_{1}\right)$ is perpendicularly applied to $\mathrm{B}_{0}$, it causes the net magnetic precession to flip on the perpendicular plan by absorbing the energy from the RF. On the removal of the RF, the net magnetic moment gradually relaxes and realigns to the direction of $\mathrm{B}_{0}$ with release of the absorbed energy. The relaxation processes can be measured by $z$-axis and $x y$-plane in 3-D directions, which are defined by longitudinal $\mathrm{T} 1$ relaxation and transverse $\mathrm{T} 2$ relaxation, respectively. Relaxation times are sensitive to microenvironments that can be affected by NPs for improved contrast. MRI signal intensities by $\mathrm{T} 1$ relaxation (longitudinal recovery signal) increase over repetition time. MRI signal intensities by $\mathrm{T} 2$ relaxation (dephasing of transverse magnetization) decrease with increased echo time (TE). ${ }^{4,5}$

MRI contrast agents change the MRI signal intensities around them by shortening either $\mathrm{T} 1$ or T2 relaxation times. ${ }^{6}$ Relaxivity values ( $1=1 / \mathrm{T} 1$ or $\mathrm{r} 2=1 / \mathrm{T} 2)$ are also usually used as a parameter to quantify MRI contrast effects by agents. Relaxivity $\mathrm{r} 1$ and $\mathrm{r} 2$ values will be affected by the magnetic field strength, but not very much. In particular, r1 relaxivity values ranging from 0.1 to 1.5 Tesla are very little affected. ${ }^{7}$ There are diverse $\mathrm{T} 1$ and $\mathrm{T} 2$ contrast agents (Table 2). T1 agents increase MRI signal intensities around them, showing bright images. Therefore, T1 agents are also

Table I Comparison of various imaging modalities

\begin{tabular}{|c|c|c|c|c|c|c|c|c|c|}
\hline Modality & Source & Typical probes & Resolution & Depth & Sensitivity§ & Time & Information & Cost US\$ & Clinical use \\
\hline MRI & $\begin{array}{l}\text { Radio } \\
\text { wave }\end{array}$ & $\begin{array}{l}\text { Paramagnetic }\left(\mathrm{Gd}^{3++}\right) \text {, } \\
\text { superparamagnetic } \\
\left(\mathrm{Fe}_{3} \mathrm{O}_{4}\right)\end{array}$ & $10-100 \mu \mathrm{m}$ & No limit & $10^{-9}-10^{-6}$ & $\begin{array}{l}\text { Minutes to } \\
\text { hours }\end{array}$ & $\begin{array}{l}\text { Anatomical, } \\
\text { physiological, } \\
\text { molecular }\end{array}$ & $>\$ 300,000$ & Yes \\
\hline CT & X-ray & $\begin{array}{l}\text { lodine, barium sulfate, } \\
\text { gold }\end{array}$ & $50-200 \mu \mathrm{m}$ & No limit & $10^{-6}$ & Minutes & $\begin{array}{l}\text { Anatomical, } \\
\text { physiological }\end{array}$ & $\begin{array}{l}\$ 100,000- \\
\$ 300,000\end{array}$ & Yes \\
\hline PET & $\gamma$-ray & $\begin{array}{l}\text { Radioisotopes (eg, }{ }^{18} \mathrm{~F} \text {, } \\
\left.{ }^{11} \mathrm{C},{ }^{13} \mathrm{~N},{ }^{15} \mathrm{O},{ }^{64} \mathrm{Cu},{ }^{124} \mathrm{l}\right)\end{array}$ & $\mathrm{I}-2 \mathrm{~mm}$ & No limit & $10^{-15}$ & $\begin{array}{l}\text { Minutes to } \\
\text { hours }\end{array}$ & $\begin{array}{l}\text { Physiological, } \\
\text { molecular }\end{array}$ & $>\$ 300,000$ & Yes \\
\hline $\begin{array}{l}\text { Optical } \\
\text { imaging" }\end{array}$ & Light & QDs, NIRF dyes & $>0.3 \mu \mathrm{m}$ & $<10 \mathrm{~cm}$ & $10^{-12}$ & $\begin{array}{l}\text { Subseconds } \\
\text { to minutes }\end{array}$ & $\begin{array}{l}\text { Physiological, } \\
\text { molecular }\end{array}$ & $\begin{array}{l}\$ 100,000- \\
\$ 300,000\end{array}$ & In development \\
\hline
\end{tabular}

Notes: ${ }^{\$}$ Moles of label detected. "Optical imaging involves fluorescence reflectance imaging, bioluminescence imaging, fluorescence-mediated tomography, and intravital microscopy. Adapted with permission from Macmillan Publishers Ltd: Nature. ${ }^{3}$ Copyright 2008; Adapted with permission from Macmillan Publishers Ltd: Nature. ${ }^{4}$ Copyright 2010; Adapted from Cheon J, Lee JH. Synergistically integrated nanoparticles as multimodal probes for nanobiotechnology. Acc Chem Res. 2008;4I(I2): 1630-1640.5

Abbreviations: MRI, magnetic resonance imaging; CT, computed tomography; PET, positron emission tomography; QDs, quantum dots; NIRF, near-infrared fluorescent. 
Table 2 Examples of MR contrast agents

\begin{tabular}{|c|c|c|c|c|}
\hline MR contrast agents & Main use & $\begin{array}{l}\text { MW }(k D) / \\
\text { particle size }(\mathrm{nm})\end{array}$ & $\begin{array}{l}\text { Relaxivity (mM/second) })^{-1 /} \\
\text { Tesla (T) }\end{array}$ & Reference(s) \\
\hline Gd-DTPA & TI & $0.6 \mathrm{kD}$ & $\mathrm{rl}=3.7,0.47 \mathrm{~T}$ & 24 \\
\hline Dextran-Gd-DTPA & TI & $75 \mathrm{kD}$ & $\mathrm{rl}=\mathrm{II}, 0.25 \mathrm{~T}$ & 24 \\
\hline Gd-DTPA-polylysine & TI & $50 \mathrm{kD}$ & $r l=13,0.47 \mathrm{~T}$ & 24 \\
\hline Gd-DTPA-24-cascade-polymer & TI & $30 \mathrm{kD}$ & $r I=10, I .5 / 2.0 \mathrm{~T}$ & 25,26 \\
\hline Gd-melanin polymer & TI & $50 \mathrm{kD}$ & $r I=20-40, N A$ & 27 \\
\hline 6-Dendrimer-Gd-DTPA & TI & $139 \mathrm{kD}$ & $\mathrm{rl}=34, \mathrm{I} .17 \mathrm{~T}$ & 28 \\
\hline $\begin{array}{l}\text { Carboxydextran-coated SPIO } \\
\left(\mathrm{SHU}-555, \text { Resovist }^{\circledR}\right)\end{array}$ & $\mathrm{T} 2$ & $62 \mathrm{~nm}$ & $r l=12, r 2=188,0.94 \mathrm{~T}$ & 29 \\
\hline $\begin{array}{l}\text { Dextran-coated SPIO } \\
\left(\text { AMI- } 25, \text { Feridex }^{\circledR}\right)\end{array}$ & $\mathrm{T} 2$ & $58 \mathrm{~nm}$ & $\mathrm{rl}=24, \mathrm{r} 2=107,0.47 \mathrm{~T}$ & 30,31 \\
\hline $\begin{array}{l}\text { Dextran-coated USPIO } \\
\left(\text { AMI-227, Combidex }{ }^{\circledR}\right)\end{array}$ & $\mathrm{T} 2$ & $17-20 \mathrm{~nm}$ & $r l=23, r 2=53,0.47 \mathrm{~T}$ & 30 \\
\hline $\begin{array}{l}\text { Dextran-coated USPIO } \\
\text { (MION-46L) }\end{array}$ & $\mathrm{T} 2$ & I8-24 nm & $r l=16, r 2=35,0.47 \mathrm{~T}$ & 32 \\
\hline MION-encapsulated liposomes & $\mathrm{T} 2$ & $170-300 \mathrm{~nm}$ & $r l=10, r 2=130,0.25 \mathrm{~T}$ & 33 \\
\hline PEGylated magnetoliposomes & T2 & $40 \mathrm{~nm}$ & $r I=3, r 2=240,0.47 \mathrm{~T}$ & 34 \\
\hline
\end{tabular}

Notes: Carboxydextran-coated SPIO (SHU-555, Resovist ${ }^{\circledR}$, Bayer Schering Pharma AG, Berlin-Wedding, Germany); Dextran-coated SPIO (AMI-25, Feridex IV ${ }^{\circledR}$, AMAG Pharmaceuticals, Lexington, MA, USA); Dextran-coated USPIO (AMI-227, Combidex ${ }^{\circledR}$, AMAG Pharmaceuticals, Lexington, MA, USA).

Abbreviations: MR, magnetic resonance; Gd, gadolinium; DTPA, diethylene triamine pentaacetic acid; USPIO, ultrasmall superparamagnetic iron oxide; MION, monocrystalline iron oxide nanoparticle; PEG, polyethylene glycol; TI, longitudinal relaxation time; T2, transverse relaxation time.

called positive contrast agents. Gd-based T1 agents have been widely applied and are being developed for human diagnosis in angiography, the gastrointestinal system, the liver, and the whole body. A problem of this agent is such side effects as nephrogenic systemic fibrosis, due to the high toxicity of Gd. Although many Gd-based contrast agents are protected in the chelate structures, such as Gd-diethylenetriamine pentaacetic acid, in some patients with renal failure, nephrogenic systemic fibrosis has been reported by using Gd-based contrast agents. ${ }^{8,9}$ On the other hand, T2 agents decrease MRI signal intensities around them, showing dark images, so the agents are also called negative contrast agents. Iron oxide $\left(\mathrm{Fe}_{3} \mathrm{O}_{4}[\mathrm{IO}]\right)$ is the most popular $\mathrm{T} 2$ agent. IO-based contrast agents have been applied in biological systems after surface change by biocompatible materials, such as dextran, polyethylene glycol (PEG), and poly(lactic-co-glycolic) acid. ${ }^{10,11}$ IO-based agents have advantages in terms of precise control, large-scale production of diverse core sizes, low toxicity, heating effects (hyperthermia), and dragging effects by an external magnet. ${ }^{12-14}$ However, due to the negative contrast effects, it is still challenging to quantitate the negative contrast effects of the agents. Therefore, in order to increase sensitivity, diverse studies have been tried, including positive contrast techniques, ${ }^{15,16}$ chemical exchange saturation transfer imaging, ${ }^{17}$ hyperpolarized ${ }^{13} \mathrm{C}$ imaging, ${ }^{18,19}$ dopant-mediated contrast agents,${ }^{20}$ and differently shaped IOs. ${ }^{21}$ In particular, the precise control of size and shape of IO can be very useful in imaging agents for nanomedicine. An earlier report demonstrated that the $\mathrm{r} 2$ relaxivity of superparamagnetic IO (SPIO)
NPs (below $30 \mathrm{~nm}$ ) increased with size, because fast diffusion averages the magnetic field owing to the NPs in this range. On the other hand, for large NPs, they can work as stationary objects instead of the diffusion effect. Large NPs exhibit the highest $\mathrm{r} 2$ relaxivity, which is not dependent on their size. Notably, since large NPs show ferrimagnetism, their magnetic dipole interaction restricts their biological application as an imaging agent. However, $22 \mathrm{~nm}$ IO nanocubes can be used as a ferrimagnetic-based imaging agent, because they can be controlled for the stable colloidal property by encapsulating the nanocubes into polymers, minimizing magnetic dipole interactions. Polymeric NPs can represent very high T2 contrast effects for MRI without serious agglomeration in the bloodstream. ${ }^{22,23}$

In summary, MRI is one of the most suitable imaging modalities to perform molecular imaging, but the low sensitivity due to the low FDA-approved magnetic field (3 Tesla) is still a challenging issue. T1 and T2 contrast agents have advantages and limitations in terms of sensitivity and toxicity, respectively. These limitations might be overcome by the development of new MRI techniques or by control of the physicochemical properties of contrast agents.

\section{X-ray imaging and computed tomography}

$\mathrm{X}$-ray and CT are 2-D and 3-D medical imaging modalities, respectively, using $\mathrm{X}$-ray beams. X-ray imaging is one of the oldest and most commonly used modalities, and has been in the clinical workplace for more than half a century. CT scanners use radioactive X-rays several times, taking 
signals obtained at different angles and processing them with a computer to reconstruct 3-D images. Using the CT scanner, various diagnostic images can be acquired, including those of the head, lungs, pulmonary angiogram, cardiac system, abdominal area, and extremities. However, overexposure to $\mathrm{X}$-rays can be harmful. In particular, radiation exposure of children has been estimated to increase the probability of lifetime cancer mortality. ${ }^{35}$ Therefore, the use of potentially harmful radiation is a shortcoming of CT scans. While CT scans can obtain detailed skeletal structures of the human body, the differentiation of morphological structures between normal and pathological tissues is limited without CT contrast agents. In the next section, we will briefly review the basic principles of X-ray imaging and CT contrast agents.

\section{Basic principles of $\mathrm{X}$-ray imaging and contrast agents} $\mathrm{X}$-ray imaging works by the difference of photon attenuation between materials. X-ray energy mass-attenuation coefficients and mass energy-absorption coefficients are the two main parameters to evaluate penetration attenuation and energy deposition caused by the materials. The mass-attenuation coefficient measures the X-ray opacity of a material, and the mass energy-absorption coefficient indicates the partial amount of ionization occurring in the material by incident $\mathrm{X}$-rays. Therefore, the performance of contrast agents for $\mathrm{X}$-ray imaging is dependent on both mass-attenuation coefficients and mass energy-absorption coefficients. ${ }^{36}$

Current contrast agents for X-ray and CT imaging are usually based on iodinated small molecules. Iodine has a high X-ray absorption coefficient. Iodine-based contrast agents have been widely applied to various purposes, including extracellular fluid, vascular space, hepatocellular, and tissuespecific imaging. ${ }^{37}$ Iodinated small molecules, however, show some problems, such as short imaging times due to rapid renal clearance and high toxicity in the kidneys. Therefore, various new contrast agents using iodine are being developed by incorporating iodinated organic compounds into NPs, such as liposomes, lipoproteins, emulsions, and polymeric NPs, to increase circulation time and to minimize toxicity in the body. ${ }^{38-41}$ As a new material, polymer-coated bismuth sulfide $\left(\mathrm{Bi}_{2} \mathrm{~S}_{3}\right)$ NPs have shown superior performance to iodine as a CT contrast agent and also demonstrated an efficient and safe profile in vivo. ${ }^{42}$ However, there are several challenges remaining, including the difficulty of controlling size and surface modification of $\mathrm{Bi}_{2} \mathrm{~S}_{3} \mathrm{NPs}$, and toxicological risks from the bismuth. Meanwhile, gold NPs have generated interest as a CT contrast agent. Gold NPs have been tried as CT contrast agents to improve on the limitations of conventional iodine contrast agents, including restricted imaging acquisition time and renal toxicity. ${ }^{43}$ Gold NPs have shown many advantages, such as easy control of sizes and shapes, biocompatibility, low toxicity, and high X-ray absorption coefficient. ${ }^{44}$ Gold NPs have also demonstrated comparable or superior performance of iodinated contrast agents for mammography and CT imaging. ${ }^{45}$ Various applications using gold NPs, such as cancer imaging and blood-pool imaging, have been demonstrated as CT contrast agents. ${ }^{46,47}$ Although further research on biodistribution, toxicity, and biocompatibility of gold NPs in the human body will be required for a long-term period, gold NP-based approaches for CT imaging could be promising.

CT using contrast agents can be one of the more powerful imaging modalities. This modality has great advantages with respect to cost, short acquisition time, and high resolution. However, the harmful effects of ionizing radiation and the need for improvement of imaging sensitivity are still limitations. It might be improved by the development of short acquisition-time techniques or dual-modality applications.

\section{Positron emission tomography and single-photon emitted tomography}

PET is a nuclear medicine imaging modality to produce 3-D functional images in the body. The positron signals $(\gamma$-rays) emitted from radioactive isotopes or tracers are detected without external excitation. Years ago, the FDA approved PET imaging as a molecular imaging technique in the clinic. ${ }^{4}$ PET shows very high sensitivity among all imaging modalities, and its penetration depth is unlimited (Table 2). Using this high sensitivity, early diagnosis and continuous monitoring of disease by PET are possible. The shortcomings of PET are very low spatial resolution, limited acquisition time owing to radioisotopes with short half-lives, and radiation to the subject.

\section{Principles of PET/single-photon emission computed tomography and contrast agents}

PET records $\gamma$-rays from the body. For that, a radioisotope with a short half-life must be injected into the body before conducting the scan. The radioisotope is incorporated with biological molecules, leading to different concentrations in tissues of interest. The radioisotope also emits a positron as it undergoes positron emission decay. The emitted positron travels and interacts with an electron, an encounter that annihilates both electron and positron, making a pair of $511,000 \mathrm{eV} \gamma$-rays moving in approximately opposite directions. ${ }^{48}$ The $\gamma$-rays are detected by a scintillator that 
converts $\gamma$-rays into visible light. A burst of the light is detected by photomultiplier or silicon avalanche photodiodes. The detection of coincident pairs of these photons is finally recorded. ${ }^{49}$

Various positron-emitting isotopes have been used, including ${ }^{18} \mathrm{~F},{ }^{15} \mathrm{O},{ }^{13} \mathrm{~N},{ }^{11} \mathrm{C},{ }^{14} \mathrm{O},{ }^{64} \mathrm{Gu},{ }^{62} \mathrm{Gu},{ }^{124} \mathrm{I},{ }^{76} \mathrm{Br},{ }^{82} \mathrm{Rb}$, and ${ }^{68} \mathrm{Ga}$, and most isotopes are produced in a cyclotron. In particular, ${ }^{18} \mathrm{~F},{ }^{15} \mathrm{O},{ }^{13} \mathrm{~N}$, and ${ }^{11} \mathrm{C}$ are the most commonly used. ${ }^{50}$ Meanwhile, many isotopes have short half-lives (eg, ${ }^{18} \mathrm{~F}=109.74$ minutes, ${ }^{15} \mathrm{O}=122.24$ seconds, ${ }^{13} \mathrm{~N}=9.97$ minutes, ${ }^{11} \mathrm{C}=20.38$ minutes), and the reaction time for the incorporation of the isotope with the parent molecule also must be considered. Therefore, a cyclotron source needs to be located near the imaging facility if shorter lifetime isotopes are used. Hospital or research sites for the imaging equip the safety areas to store and handle the radioactive isotopes. A similar technique is single-photon emission computed tomography (SPECT). For SPECT imaging, different isotopes are used (eg, ${ }^{99 \mathrm{~m}} \mathrm{Tc},{ }^{131} \mathrm{I},{ }^{123} \mathrm{I},{ }^{111} \mathrm{In}$ ). The sensitivity of SPECT is less than PET, but SPECT can visualize different radioisotopes at the same time, because different isotopes emit different $\gamma$-rays of different energies in SPECT. On the other hand, since all isotopes in PET emit the same energy, two different isotopes must be injected sequentially, allowing the decay of the first isotope. ${ }^{4}$

PET and SPECT have the highest sensitivity for imaging among current imaging modalities. By linking these PET probes to molecules involved in cellular metabolism, hotspots of metabolism, such as actively growing tumors, can be detected on the basis of metabolism rather than just structure. However, the spatial resolution is worse than MRI or CT. Also, the short imaging time, radiation safety, and cost problem for installing a cyclotron are current limitations of those imaging modalities. However, as applications for multimodality imaging, the combination of PET or SPECT with MRI or CT could be the most promising way for synergistic effects from the multimodality strategy. Meanwhile, in the design of the multimodality NPs, the sensitivity of each modality must be considered in detail. For example, for MRI-PET dual-modality imaging, PET images could be easily saturated by the NPs, but MRI images could provide very weak signals by the NPs with the same amount. Therefore, the trade-off between the modalities should be carefully considered for MRI-PET dual-modality imaging.

\section{Optical imaging}

In vivo optical imaging has attracted much interest due to its noninvasive, highly sensitive, cost-effective, nonionizing, and real-time imaging features. Currently, various studies of molecular imaging have been achieved by in vitro and ex vivo systems. However, the fundamental limitations of optical imaging are light scattering, autofluorescence, and absorption by adjacent tissues, water, and lipids from in vivo systems; therefore, optical imaging for in vivo systems has many limitations, in particular owing to small penetration depths (typically $<1 \mathrm{~cm}$ ). However, some advanced techniques have improved on these limitations (eg, fluorescence, bioluminescence, diffused optical tomography, and optical coherence tomography). ${ }^{3}$ In particular, near-infrared fluorescent (NIRF) imaging is a current method widely applied for in vivo small-animal imaging. This review will focus on NIRF imaging techniques and NIRF probes.

\section{Principles of NIRF imaging and contrast agents}

Fluorescence imaging is made by exciting certain fluorophores using external light and by detecting the emission using a highly sensitive charge-coupled device camera. The fluorophores can be endogenous molecules, like hemoglobin, or can be exogenous ones, like synthetic optical probes (eg, fluorescein isothiocyanate, rhodamine). However, in vivo fluorescence imaging still has limited penetration depth, because hemoglobin absorbs visible light, and also water and lipids absorb IR light. Meanwhile, light in the NIR window $(650-900 \mathrm{~nm})$ has better penetration by minimizing the autofluorescence from hemoglobin, water, and lipids. ${ }^{6,51}$

Several kinds of NIR fluorophores have been developed for in vivo imaging: 1) synthetic fluorophores (eg, cyanine [Cy]), 2) synthetic fluorescence semiconductor nanocrystals (eg, quantum dots [QDs]), and 3) upconverting nanomaterials based on rare-earth ions. NIR synthetic fluorophores are most commonly used for in vivo NIRF imaging. There are some synthetic Cy analogs, such as indocyanine green, Cy5, Cy5.5, $\mathrm{Cy} 7$, and $\mathrm{Cy} 7.5$, which are all commercially available. These fluorophores can be used directly, and also can be modified with NPs or small molecules for different applications. ${ }^{52,53}$ Notably, a carbocyanine analog, indocyanine green, was the first fluorophore approved to test hepatic function in the 1970 s, and it has been used in humans as well as animals for cancer detection using optical imaging. ${ }^{54,55}$

QDs are inorganic semiconductor nanocrystals that are used as NIR fluorophores. They typically have a core-shell structure and are 2-8 $\mathrm{nm}$ in diameter. QDs have broad absorption spectra and also show narrow emission spectra, which are tunable by changing compositions and sizes. They also show high photostability. QDs emitting in NIR regions include $\mathrm{CdSe}, \mathrm{CdTe}, \mathrm{GaAs}, \mathrm{HgTe}$, InAs, InP, PbSe, 
and $\mathrm{PbTe}$, and these QDs can be further tuned in emission and lifetimes. ${ }^{4}$ Since most QDs are synthesized in organic solvents, they cannot be dissolved in aqueous buffers without further surface modifications. These modifications have been tried though various methods: 1) ligand exchange by using thiol-containing molecules, 2) encapsulation by amphiphilic polymers, and 3) combinations of layers with different molecules. ${ }^{56}$ Water-soluble QDs can be tested in biological environments. However, the potential toxicity effect of QDs is still controversial and needs to be further studied. It may be limited to ex-vivo NIRF imaging for humans.

Upconversion fluorescence is a nonlinear optical process that converts two or more photons to a higher-energy output photon. ${ }^{57}$ The upconversion technique using lanthanide rare-earth ions (such as $\mathrm{Er}^{3+}, \mathrm{Yb}^{3+}, \mathrm{Nd}^{3+}, \mathrm{Ho}^{3+}$, and $\mathrm{Pr}^{3+}$ ) has been noticed as an alternative technique to enhance tissuepenetration depth and signal-to-noise ratios. The lanthanidedoped NPs also showed sharp fluorescence, long lifetime of fluorescence, good photostability, and low toxicity. ${ }^{58,59}$ However, the upconversion techniques also have a potential problem if the fluorescence emits in the visible region after absorbing the energy in NIR regions. The fluorescence in the visible region can also undergo tissue-penetration issues. As a good example, therefore, Wang et al reported on the upconversion NPs that emit NIRF luminescence $-831 \mathrm{~nm}$ by using excitation of $980 \mathrm{~nm}$ - to minimize the absorption problems. ${ }^{60}$

In summary, optical imaging has various advantages, including high sensitivity, low cost, short acquisition time of images, and safety. While it is true that NIR fluorophores improve tissue-penetration depth, the depth is not still sufficient to overcome a big hurdle for human in vivo imaging. However, using NIR fluorophores, fluorescence image-guided surgery systems are currently being tried. For example, NIRF-guided sentinel lymph-node mapping techniques could be a promising way in the near future to evaluate lymphatic metastasis in humans. ${ }^{61,62}$

In the previous section, we reviewed four imaging modalities (MRI, CT, PET/SPECT, and optical imaging) widely applied in both research and clinical fields. They have both strengths and weaknesses for in vivo imaging. In the next section, we will review some advanced approaches to compensate for the weaknesses from a single imaging modality by using dual-modality strategies. This review will introduce the combination techniques of both MRI-PET/SPECT and MRI-optical imaging, and also some other techniques using different imaging modalities.

\section{Specific examples of nanomaterials for imaging}

A strong motivation for multimodality imaging is that currently available single imaging modalities often make many errors, such as true-negative or false-positive results in the diagnosis of patients with cancer. While new NPs have been reported to minimize the errors, demonstrating their new capabilities through cell experiments or in vivo small animal experiments, most NPs were not able to be translated to clinical sites for human application. The NPs, which can be evaluated by only one imaging modality, cannot provide enough and exact information in the human body with respect to anatomical, physiological, or molecular information (Table 1). In this respect, multimodality approaches could be a promising way to translate current techniques from research fields to clinical sites. Multimodality imaging techniques using multimodal NPs can provide much more information by combining advantages and compensating for limitations from a single imaging modality to visualize the effects of the NPs. There are many possible combinations for dual-modal, trimodal, or other imaging modalities, including MR-optical, MR-PET, PET-CT, optical-PET, MR-CT, and MR-PET-optical. Various applications for multimodal imaging have been reported, and the following sections introduce some specific examples about it (Figure 1). ${ }^{63-65}$ PET-CT dual-modality imaging technologies have been commercialized for the human body, and the PET-MR dualimaging modality is available for small-animal imaging. ${ }^{66,67}$ With multimodal NPs, multimodality imaging can minimize errors in the diagnosis of patient disease. Another potential of multimodal NPs is successively tracking them from the whole body through small tissues to cellular levels using several imaging modalities. For example, multimodal NPs can be used to visualize physiological changes for in vivo systems using PET or to visualize anatomical information with high resolution using either MRI or CT. The NPs can be subsequently further investigated at the cellular or subcellular levels by using optical microscopy or transmission electron microscopy. In this review, we focus on studies of NPs for MR-optical or MR-PET/SPECT dual-modality imaging. MRI can provide anatomical and physiological images inside the human body with high spatial resolution, but MRI agents are not currently of sufficient sensitivity. While optical or radionuclide imaging provide physiological and molecular information with high sensitivity, they have poor spatial resolutions for good anatomical images (Table 1). Therefore, either MRI-optical or MRI-PET/SPECT in combination could provide highly promising ways for dual-modality imaging strategy in the 


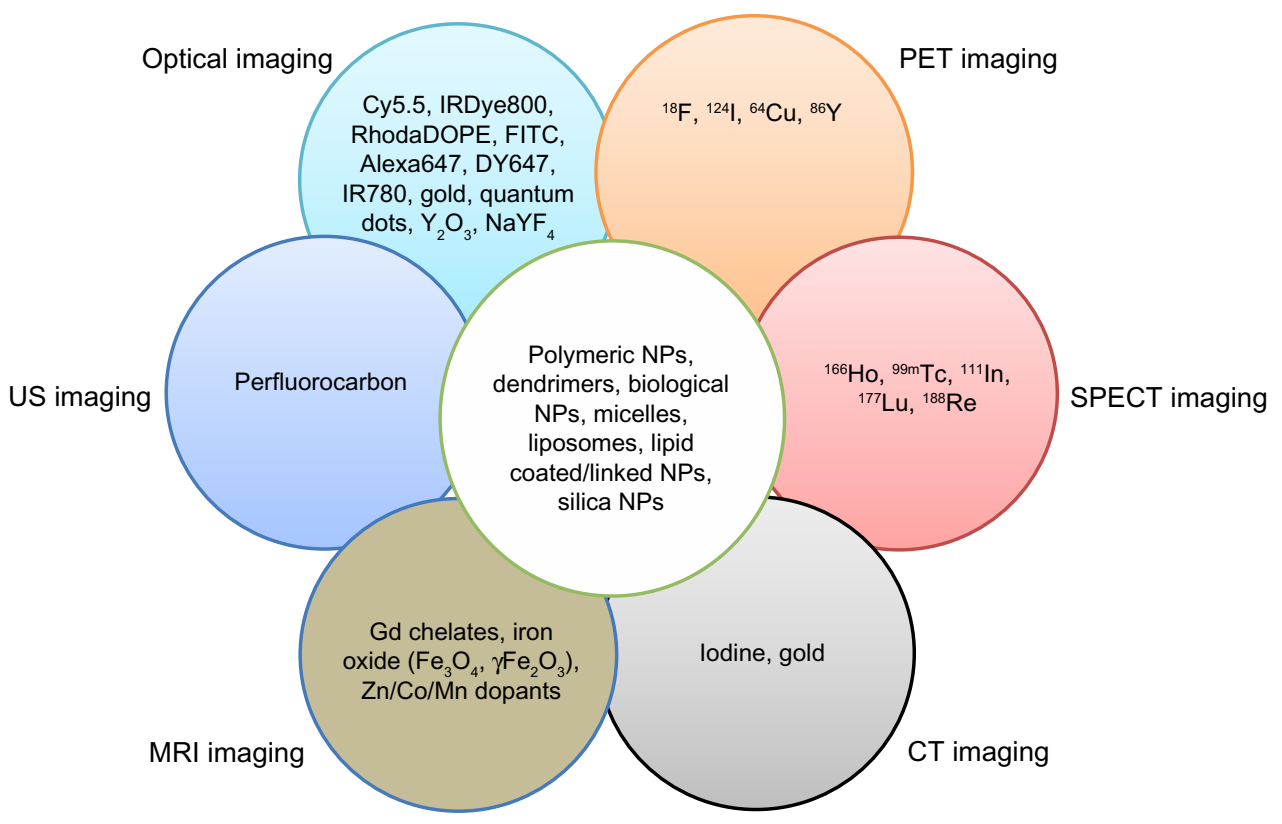

Figure I Incorporation of various contrast agents for multimodality imaging.

Notes: Data from Swierczewska et al, ${ }^{63}$ Lee et al, ${ }^{64}$ and Louie. ${ }^{65}$

Abbreviations: DOPE, I,2-dioleoyl-sn-glycero-3-phosphoethanolamine; FITC, fluorescein isothiocyanate; Gd, gadolinium; PET, positron emission tomography; US, ultrasound; NPs, nanoparticles; SPECT, single-photon emission computed tomography; MRI, magnetic resonance imaging.

near future. In addition, we also introduce other combinations (eg, ultrasound [US]) for multimodality imaging at the end of this section.

\section{MR-optical dual-modality in vivo imaging}

A big advantage of MRI-optical dual-modality imaging is that it is safe in humans. Both MRI and optical imaging are free from harmful radiation, such as X- or $\gamma$-rays. In particular, MRI-NIRF dual-modal NPs can get both anatomical and physiological information from deep inside the body using MRI and also get much more sensitive information at the molecular level using NIRF imaging. MRI-NIRF NPs for dual-modality in vivo imaging are made by chemically or physically combining such multicomponents as IO or Gd for MR and NIRF imaging probes, such as synthetic fluorophores, fluorescent semiconductor nanocrystals, or upconverting nanomaterials. For example, Nam et al have conjugated both Gd and Cy5.5 on the glycol chitosan partially modified with hydrophobic $\beta$-cholanic acid for tumor imaging (Cy5.5-CNP-Gd[III] NPs). The combination of Gd with NIRF synthetic fluorophores can be utilized for T1 (positive) contrast effects in MRI and for NIRF imaging. Their NPs of self-assembled spherical shapes were used to visualize squamous carcinoma cells (SCC7) tumors, which were implanted beneath the skin (Figure 2) ${ }^{68}$

NIRF imaging techniques have limited tissue-penetration depth, but can be used for in vivo imaging in mice.
However, NIRF imaging can also be applied to NIRF imageguided surgery in humans, where surgical resection bypasses the tissue-depth problem. Nguyen et al reported NPs enabling preoperative whole-body tumor detection in mice by MRI and NIRF image-guided delineation of the tumor margin. They used dendrimers with conjugated $\mathrm{Cy} 5, \mathrm{Gd}$, and cell-penetrating peptides. This approach can be useful to provide an objective way to differentiate tumor cells from normal cells. ${ }^{69}$ SPIO recently emerged as a T2 MRI contrast agent showing dark contrast effects in MRI, and also several applications using SPIO for dual-modality imaging have been reported. ${ }^{23,70,71}$ In addition to excellent MRI contrast effects, SPIOs have several potential advantages for nanomedicine, such as hyperthermia by converting the energy absorbed from applied alternatingcurrent magnetic fields to thermal energy for highly targeted hyperthermia, with precisely controllable size and shape and relatively low toxicity effects..$^{72}$ Our group has demonstrated MRI-NIRF in vivo dual-modality imaging using SPIOs and Cy5.5. We constructed multicomponent NPs by conjugating glycol chitosan partially modified with hydrophobic moieties with Cy5.5 and then physically loading the SPIOs (around $10 \mathrm{~nm}$ in diameter) into the core parts of NPs. The NPs showed T2 contrast effects for MRI, and showed these contrast effects at murine bladder tumor (MBT-2) sites by the accumulation of these NPs within the leaky vasculature through enhanced permeability and retention (EPR) effects (Figure 3)..$^{70,71,73}$ Chen et al reported arginine-glycine-aspartic acid triblock 


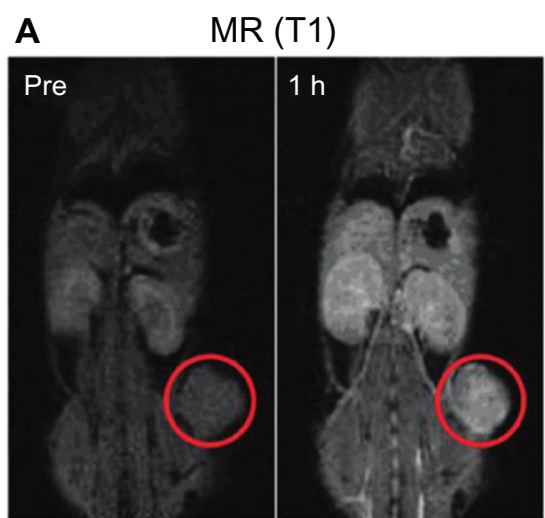

B NIRF

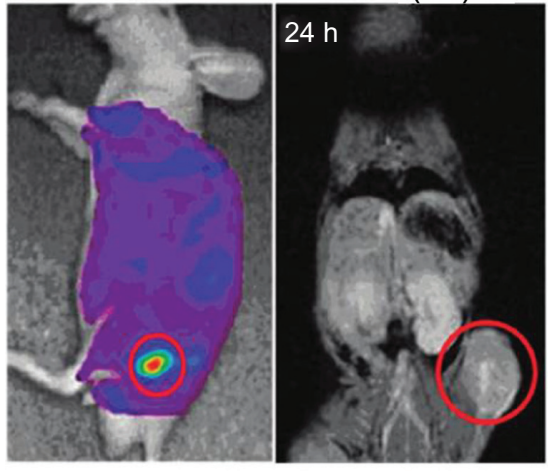

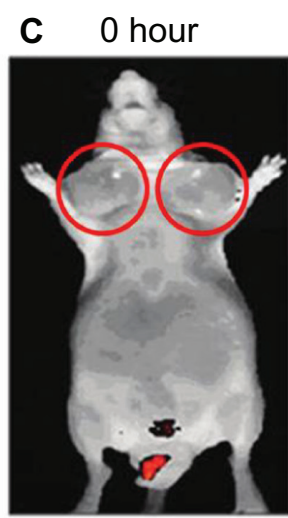

1 day

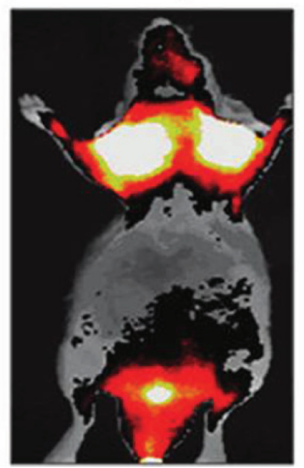

6 hours

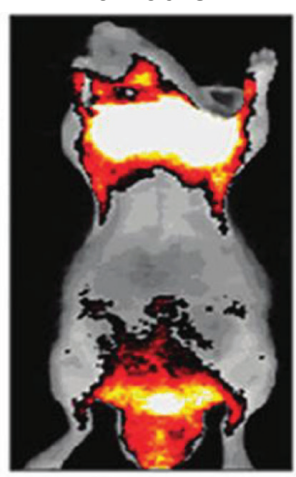

2 days

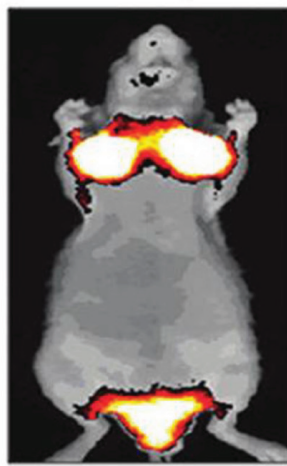

12 hours

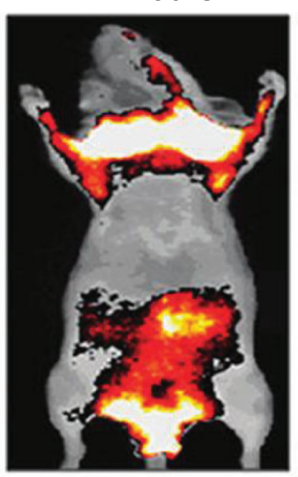

3 days

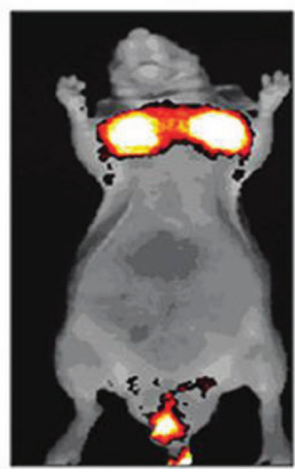

Figure 2 (A-C) In vivo magnetic resonance (MR)-near-infrared fluorescent (NIRF) dual-modality imaging of SCC7 tumors.

Notes: Cy5.5-chitosan nanoparticle-Gd(III) nanoparticles were injected into the SCC7-bearing mice, and the mice were visualized by using MR and NIRF imaging. Red circles indicate tumor sites. (A) In vivo MR imaging showed TI-positive contrast effects I hour after injection at the tumor sites. (B) In vivo NIRF imaging showed brighter NIRF intensity at the tumor site. In vivo MR imaging 24 hours after injection showed bright contrast effects at the tumor site. (C) In vivo NIRF imaging showed the accumulated Cy5.5-CNP-Gd(III) nanoparticles over time at the tumor sites. Reproduced with permission Nam T, Park S, Lee SY, et al. Tumor targeting chitosan nanoparticles for dualmodality optical/MR cancer imaging. Bioconjug Chem. 2010;21(4):578-582. ${ }^{68}$ Copyright (C) 2010 American Chemical Society.

copolymer-coated IO NPs (RGD-TPIO) for U87MG human glioblastoma imaging. They conjugated IRDye800 as a NIRF dye and also conjugated integrin $\alpha_{\mathrm{v}} \beta_{3}$ targeting cyclic RGD peptide to enhance the tumor-targeting capability. Integrin $\alpha_{\mathrm{v}} \beta_{3}$ is a cell-adhesion molecule that is closely related to tumor angiogenesis and metastasis. The use of targeting ligands can enhance the targeting capability of a certain disease, and it may enhance the retention time of the NPs in the disease sites with the EPR effect (Figure 4). ${ }^{74}$

MR-NIRF dual-modality imaging can be also achieved by combining SPIOs as MRI contrast agents and QDs as semiconductor nanocrystals for NIRF imaging. QDs also have excellent photostability, so this combination can allow long-term dual-modality imaging. For example, Tan et $\mathrm{al}^{75}$ demonstrated QD-SPIO NPs through in vivo systems where they coencapsulated QDs and SPIOs in NPs of poly(lactic acid)-D-alpha-tocopheryl polyethylene glycol 1000 succinate for Michigan Cancer Foundation (MCF-7) breast cancer imaging. In another paper, Zhou et $\mathrm{al}^{76}$ suggested a new MRNIRF dual-modality technique by using rare-earth nanocrystals.
They synthesized $\mathrm{Tm}^{3+} / \mathrm{Er}^{3+} / \mathrm{Yb}^{3+}$ codoped $\mathrm{NaGdF}_{4}$ upconversion nanophosphors. The NPs showed NIR-to-NIR luminescence, and also showed high $\mathrm{r} 1$ relaxivity in MRI. The NPs were evaluated with mice models. The upconversion nanophosphors have the potential to emit higher NIRF intensities, enhancing tissue-penetration depth.

Meanwhile, the use of dopants can provide advanced functionality for imaging as well as therapy. Tian et al demonstrated multimodality NPs for MRI-IR thermal imaging. They synthesized ultrasmall ( $<10 \mathrm{~nm}) \mathrm{Fe}_{3} \mathrm{O}_{4} @ \mathrm{Cu}_{2-x} \mathrm{~S}$ core-shell NPs. Interestingly, the NPs can be used for IR thermal imaging due to their high absorption in the NIR region (around $960 \mathrm{~nm}$ ) as well as T2-weighted MRI. The thermal effects can also be tuned by varying the amount of $\mathrm{Cu}$, optimizing the therapy effects. This approach could be useful for diagnosis and therapy at the same time. ${ }^{77}$ Huang et al recently demonstrated nanocubes (150-180 nm, 160-200 nm), composed of $\mathrm{Mn}_{3}\left[\mathrm{Co}(\mathrm{CN})_{6}\right]_{2} @ \mathrm{SiO}_{2}$. The nanocubes were used for MR and two-photon fluorescence dual-modality imaging. The silica-coated nanocubes were readily internalized into cells 


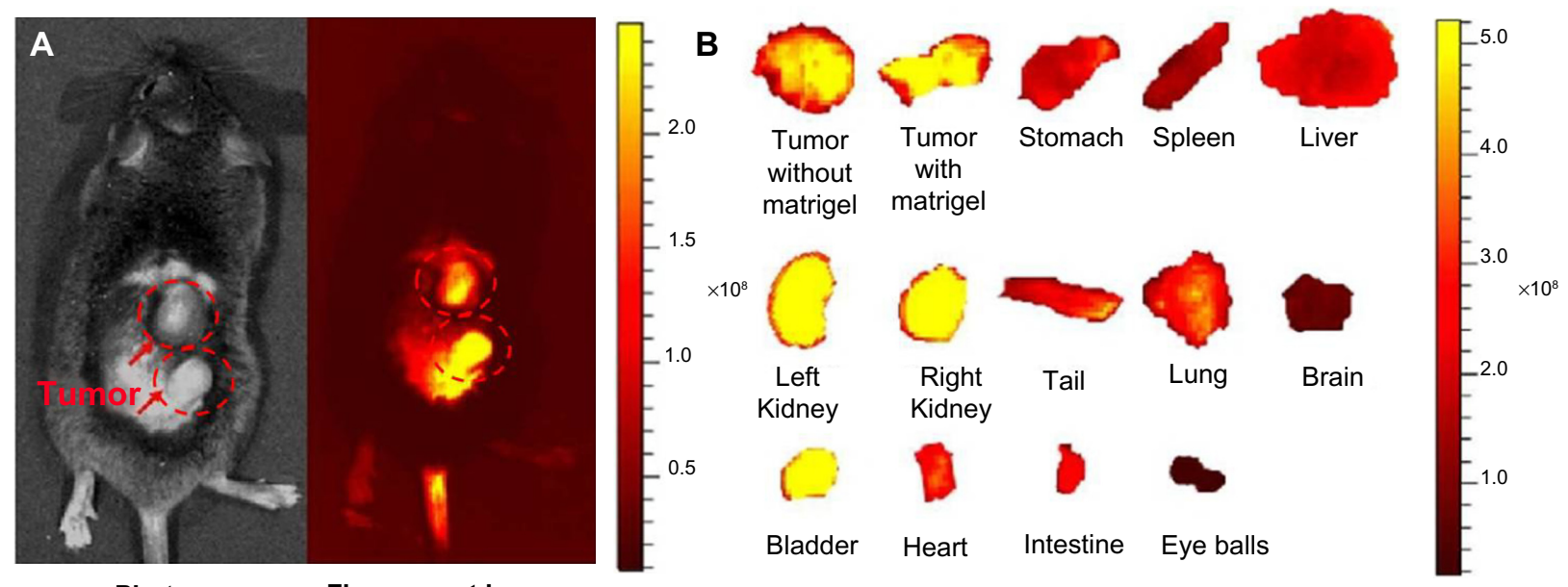

Photo

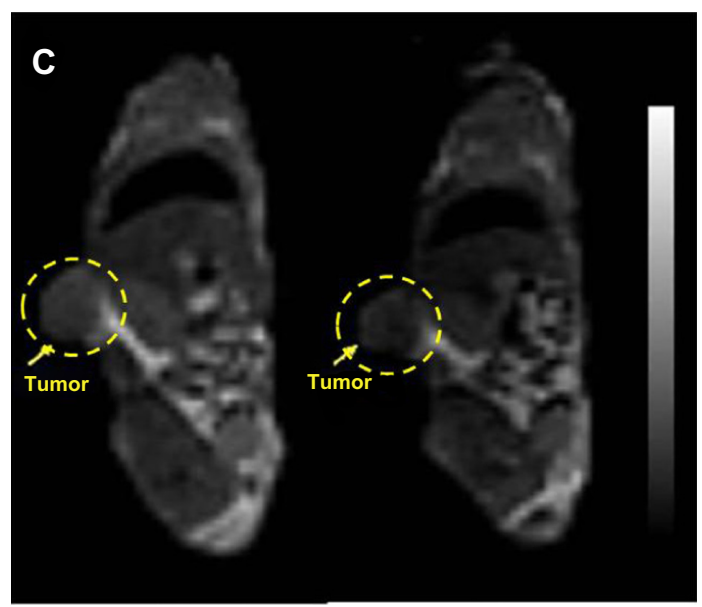

Preadministration

Postadministration

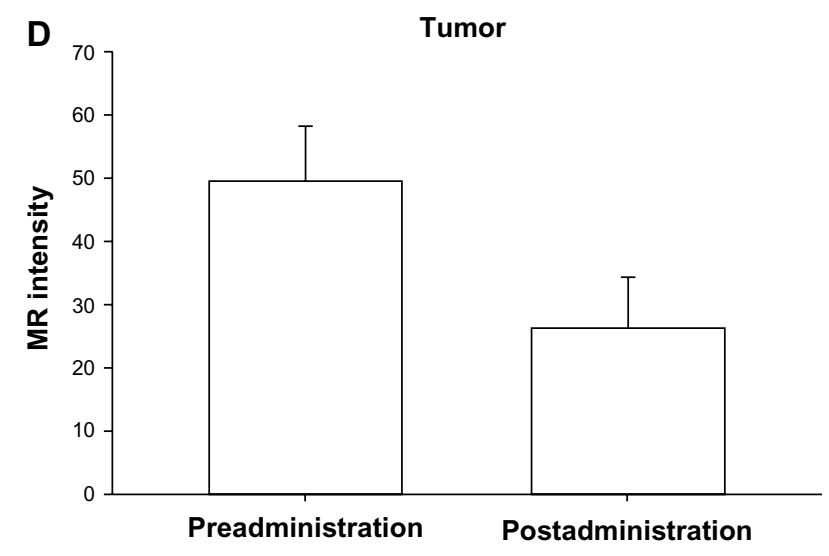

Figure 3 (A-D) In vivo magnetic resonance (MR)-near-infrared fluorescent (NIRF) dual-modality imaging of murine bladder tumor (MBT-2). SPIO-Cy5.5 conjugated glycol chitosan-based nanoparticles were injected into the tail vein for tumor detection.

Notes: (A) In vivo NIRF image; (B) ex vivo NIRF image; (C) in vivo MR image; (D) quantification of intensity at the tumor site. The dashed circles indicate the location of the implanted tumors. Reproduced with permission from Key J, Kim K, Dhawan D, et al. Dual-modality in vivo imaging for MRI detection of tumors and NIRF-guided surgery using multi-component nanoparticles. Vol: Proc SPIE. 20I I;79087:90805. ${ }^{70}$ Copyright () 201 I Society of Photo Optical Instrumentation Engineers.

A

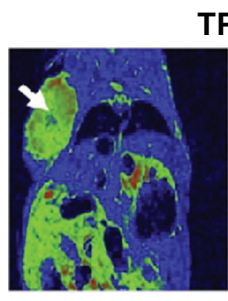

TPIO
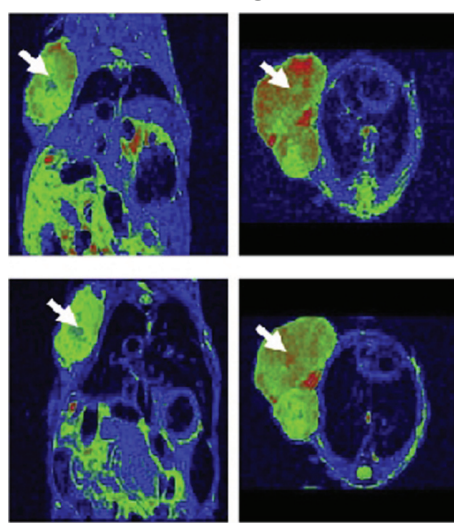

Coronal

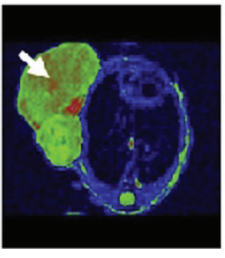

Transverse
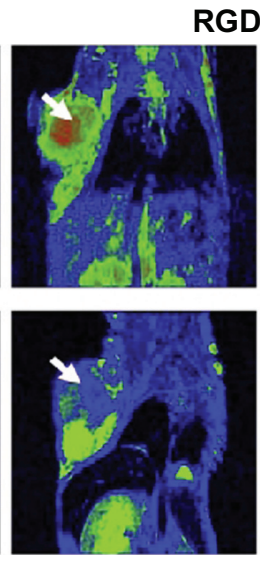

Coronal
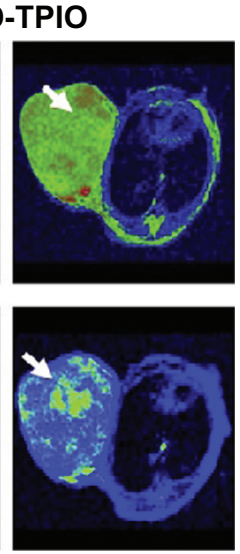

Transverse
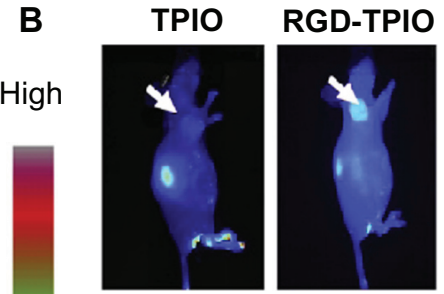

4 hours
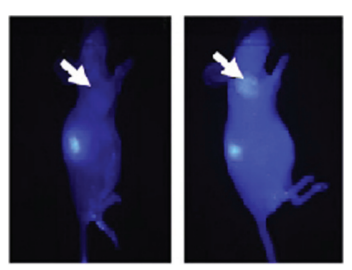

24 hours

Figure 4 In vivo magnetic resonance (MR)-near-infrared fluorescent imaging of U87MG tumor. Images were taken before and after injection of nanoparticles (NPs) using MR imaging and optical imaging.

Notes: (A) Arginine-glycine-aspartic acid (RGD) triblock copolymer-coated iron oxide (TPIO) NPs showed better T2 contrast effects in MR imaging at the tumor sites; (B) the contrast effect with RGD-TPIO NPs was also validated by optical imaging. Reprinted from Chen K, Xie J, Xu H, et al. Triblock copolymer coated iron oxide nanoparticle conjugate for tumor integrin targeting. Biomaterials. 2009;30(36):6912-6919. With permission from Elsevier. (C) 2009 Elsevier. ${ }^{74}$ 
without showing high toxicity. Also, from the Mn and Co, they showed high r1 $\left(4.7 \mathrm{mM}^{-1} \mathrm{~s}^{-1}\right)$ and $\mathrm{r} 2\left(173.1 \mathrm{mM}^{-1} \mathrm{~s}^{-1}\right)$ relaxivity and also offer high fluorescent intensities at twophoton excitation $(720 \mathrm{~nm})$ and conventional fluorescence (403 or $488 \mathrm{~nm}) .^{78}$

In summary, the combination of MR and optical imaging can provide much more information using MRoptical dual-imaging modality NPs. Current applications are still limited in small-animal models due to limited tissue-penetration depth. However, the approaches of diagnosis by MRI following by NIRF image-guided surgery could represent an important new advance applied to humans.

\section{MR-PET/SPECT dual-modality in vivo imaging}

The combination of MRI with PET or SPECT is synergistic. PET/SPECT provides excellent sensitivity, but relatively poor spatial resolution. MRI can provide excellent spatial resolution of soft tissue that is superior to $\mathrm{CT} .{ }^{79}$ Furthermore, the combination of MRI-PET/SPECT will require less overall radiation-dose exposure to the patient. Since both of these two imaging modalities are currently used for human diagnosis, once MRI-PET/SPECT dual modality is developed, the NPs can be directly applied to humans without such limitations as the limited penetration depth of optical imaging. This synergic combination of PET/SPECT and MRI is likely to become the next generation of dual-modality imaging for human diagnosis.

Magnetic NPs for MRI contrast effect can also be coupled with radioactive isotopes. Torres Martin de Rosales et al synthesized ${ }^{64} \mathrm{Cu}^{\text {II }}$-Bis (dithiocarbamatebisphosphonate) conjugated with dextran-coated SPIO NPs. They demonstrated MR-PET imaging of lymph nodes with the comparison of an image of PET-CT. ${ }^{80}$ They also reported an MR-SPECT imaging agent based on the conjugation of radiolabeled bisphosphonates ( ${ }^{99 \mathrm{~m}}$ Tc-dipicolylamine[DPA]-alendronate) to SPIOs. They demonstrated the possibility for MR-SPECT dual-modality imaging agents by showing the colocalization of NPs in spleen and liver in MR and SPECT images (Figure 5). ${ }^{81}$

Choi et al demonstrated an MR-PET dual-modality imaging agent to visualize sentinel lymph nodes. They used Mn-doped $\mathrm{Fe}_{2} \mathrm{O}_{4}$ (MnMEIO) for high MRI contrast effect, and the surface of the MnMEIO was exchanged with serum albumin (SA) for high colloidal stability. The tyrosine residue in SA-MnMEIO was directly conjugated to PET radionuclide ${ }^{124} \mathrm{I}$ ( $\left.{ }^{124} \mathrm{I}-\mathrm{SA}-\mathrm{MnMEIO}\right) .{ }^{124} \mathrm{I}-\mathrm{SA}-\mathrm{MnMEIO}$ NPs were injected into the forepaw of a rat, the position of the brachial lymph nodes was colocalized in MRI and PET, providing anatomical and physiological information from two imaging modalities (Figure 6). ${ }^{82}$

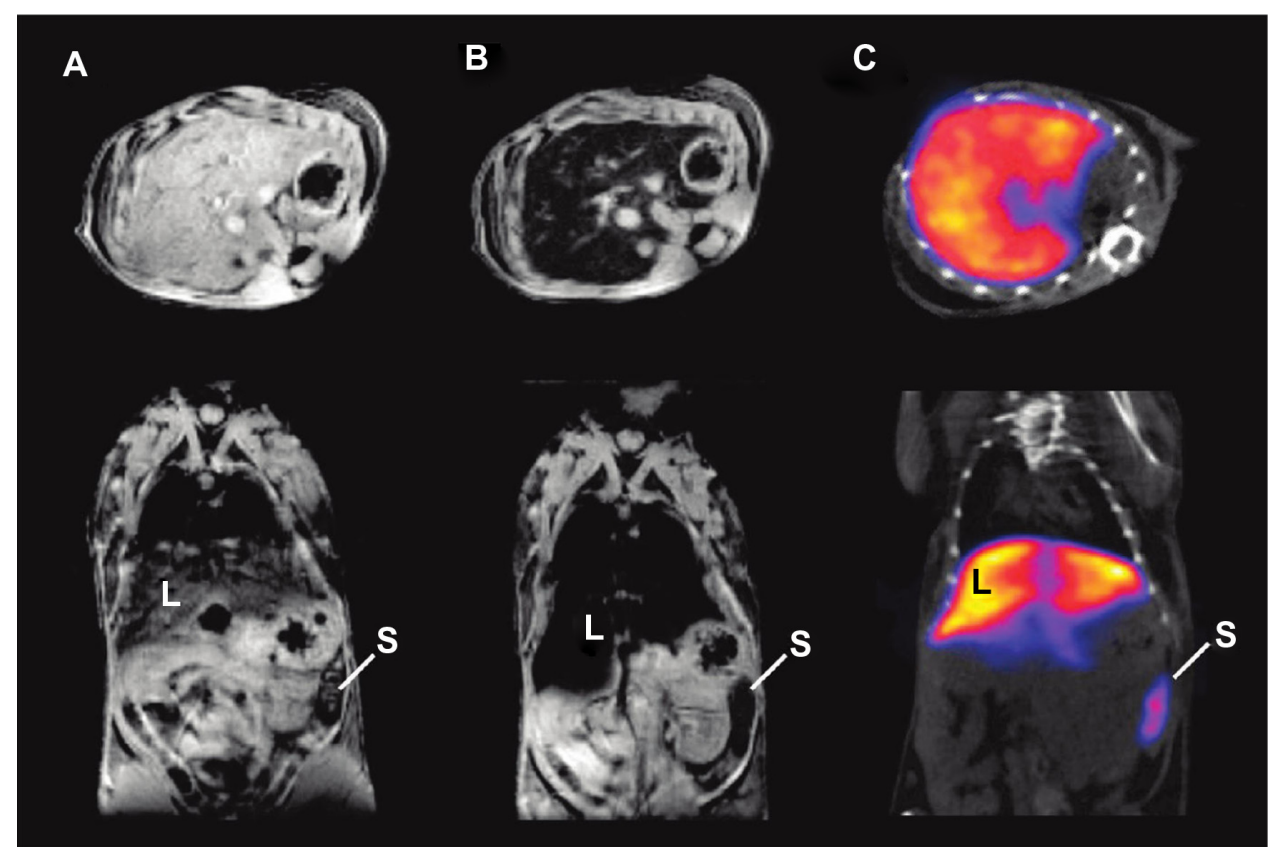

Figure 5 (A-C) In vivo magnetic resonance (MR)-single-photon emitted tomography (SPECT) images of axial view (top) and coronal view (bottom). Notes: (A) T2*-weighted MR images before injection of technetium-99m-diethylene triamine pentaacetic acid (99mTc-DTPA)-ale-Endorem; (B) T2*-weighted MR images 15 minutes after injection of ${ }^{99 \mathrm{~m} T c-D T P A}$-ale-Endorem; (C) SPECT image 45 minutes after injection of ${ }^{99 \mathrm{~m} T c-D P A-a l e-E n d o r e m}$; $L$ indicates the liver, $S$ the spleen, showing the accumulation of ${ }^{99 \mathrm{~m} T c-D P A-a l e-E n d o r e m ~ a t ~ t h o s e ~ o r g a n s ~ w i t h ~ M R ~ i m a g i n g ~ a n d ~ S P E C T ~ a f t e r ~ i n j e c t i o n . ~ R e p r o d u c e d ~ w i t h ~ p e r m i s s i o n ~ f r o m ~ T o r r e s ~ M a r t i n ~ d e ~ R o s a l e s ~ R, ~ T a v a r e ́ R, ~}$ Glaria A, Varma G, Protti A, Blower PJ. ( ${ }^{99} \mathrm{~m}$ )Tc-bisphosphonate-iron oxide nanoparticle conjugates for dual-modality biomedical imaging. Bioconjug Chem. 20I I;22(3):455-465. ${ }^{82}$ Copyright (C) 201 I American Chemical Society. 
Uppal et al synthesized by means of partial exchange of $\mathrm{Gd}$ (a six-amino acid cyclic peptide conjugated to four $\mathrm{Gd}$ tetraazacyclododecane tetraacetic acid-type chelate) and ${ }^{64} \mathrm{Cu}$. The NPs can visualize fibrin by specific binding with the NPs in both MRI and PET. They evaluated the fibrin imaging effect by injecting their NPs into the right internal carotid artery of a rat. ${ }^{83}$ Yang et al demonstrated MRI-PET dual-modality NPs, adding the function of drug delivery to treat tumors. They synthesized the NPs using cyclo(Arg-Gly-Asp-D-Phe-Cys) peptides as tumor-targeting ligands, ${ }^{64} \mathrm{Cu}$ with a macrocyclic chelating agent (1,4,7-triazacyclononane-1,4,7-triacetic acid) for PET imaging, and doxorubicin-conjugated SPIOs for tumor treatment and MRI. The multifunctional NPs had the potential for both tumor-targeting drug delivery and PET/MRI. ${ }^{79}$

Zhu et al demonstrated SPECT-NIRF dual-modality NPs in which D-glucosamine conjugated to cross-linking micelle was labeled by both NIRF fluorophore and ${ }^{111}$ In. NPs of about $25 \mathrm{~nm}$ in size were accumulated in human epithelial carcinoma A-431 xenograft mouse models, showing higher accumulation at 24 hours than 4 hours. However, the NPs showed even higher accumulation in the stomach, intestine, muscle, and bone tissues than in tumors. This unexplained, nonspecific accumulation could be a potential problem of these NPs. ${ }^{84}$

In summary, the combination of MRI and PET has the potential for the best simultaneous spatial resolution and physiological information among clinically used imaging modalities. However, there are still challenging issues, including the restricted time of radioisotopes, the difficulty of image registration, and the very high cost for setting up these imaging facilities.

\section{Other multimodality imaging techniques}

CT has good resolution for anatomical information, and can also provide 3-D tomography faster than MRI. However, CT has poor contrast for soft tissue, and does not give physiological information. CT contrast can be improved by the use of targeted NPs with electron-dense core materials. Therefore, when CT
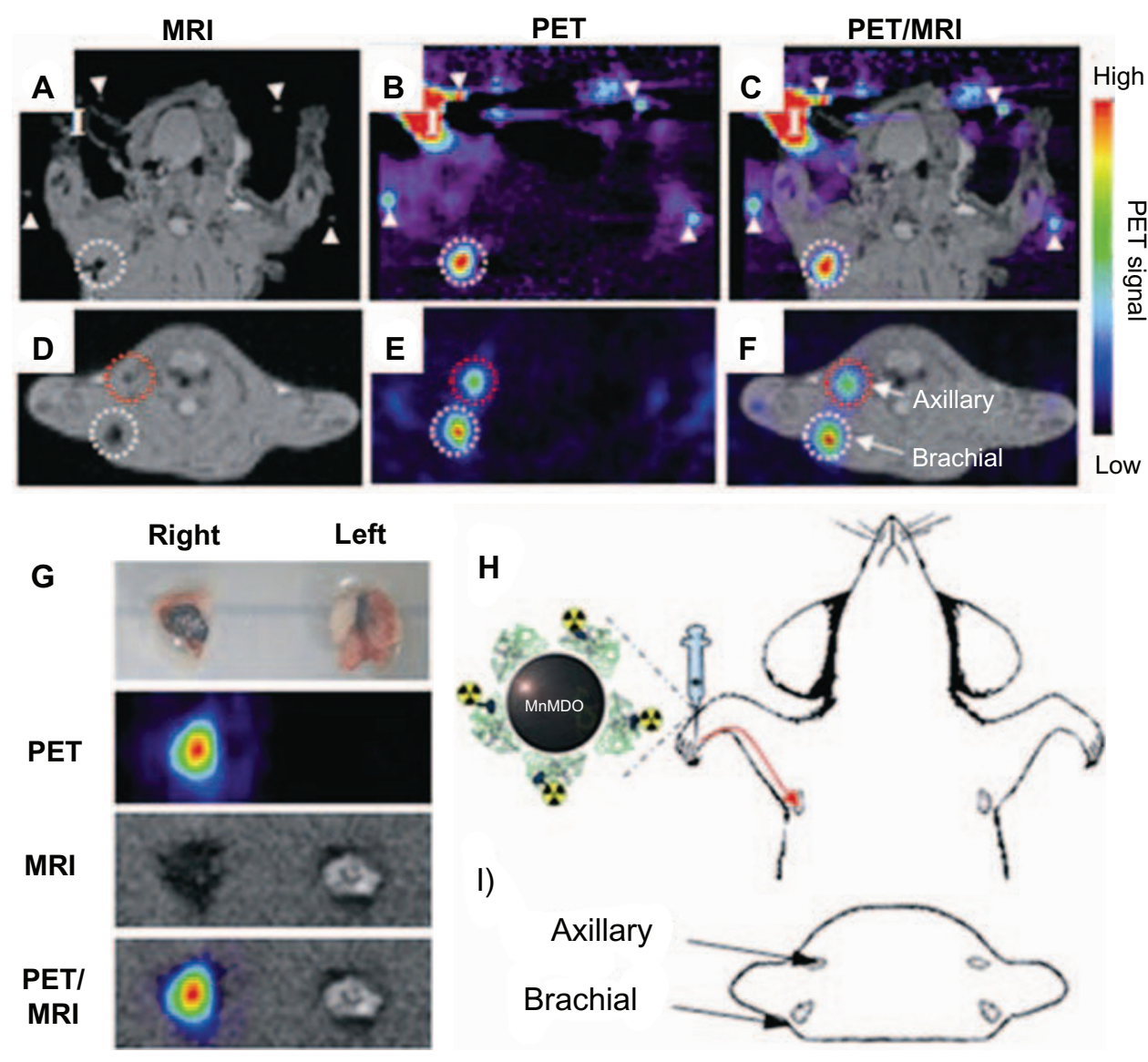

Figure 6 (A-I) In vivo magnetic resonance (MR) and positron emission tomography (PET) images of sentinel lymph nodes in a rat I hour after injection of iodine- I24-serum albumin-manganese magnetism-engineered iron oxide into the right forepaw.

Notes: Coronal images of $(\mathbf{A})$ in vivo MR, (B) in vivo PET, (C) MR-PET fusion; transverse images of (D) in vivo MR, (E) in vivo PET, (F) MR-PET fusion; (H) explains the coronal images of $(\mathbf{A}-\mathbf{C})$; (I) describes transverse directions of (D-F); (G) ex vivo images of brachial lymph nodes by PET, MR imaging, and PET/MR imaging; (I) in (A-C) indicates the injection site. Reproduced with permission by Choi JS, Park JC, Nah H, et al. A hybrid nanoparticle probe for dual-modality positron emission tomography and magnetic resonance imaging. Angew Chem Int Ed Engl. 2008;47(33):6259-6262. 
images are combined with MRI or NIRF, these shortcomings can be overcome. By the combination of MRI with CT, the resolution of the soft tissue can be improved, and also the MRI-CT multimodality contrast agents visualize the colocalized position of the NPs in both imaging modalities. For the CT-NIRF combination, while NIRF imaging is possible for small animals only, the NIRF signals can be further investigated for ex-vivo analysis of necropsied tissues and organs. Gold NPs have been most commonly demonstrated as a CT contrast agent due to precise size control, good biocompatibility, and easy surface modification. Gold NPs combined with SPIOs can be used for CT-MRI dual-modality NPs. For example, Kim et al demonstrated gold and SPIO hybrid NPs in which components were combined by thermal decomposition. These hybrid NPs were further coated by amphiphilic dodecyl methacrylate (DMA), methacrylic acid (MA), poly(ethylene glycol) methyl ether methacrylate (mPEGMA) for in vivo applications. Systemically injected gold-IO hybrid NPs showed time-dependent contrast effects at the hepatoma regions of mouse models for 24 hours. ${ }^{43}$

Sun et al demonstrated NIRF-CT multimodality NPs where gold NPs were encapsulated by Cy5.5 conjugated glycol chitosan polymers. The Cy5.5 NIRF dyes were further modified with peptides that were matrix metalloproteinase (MMP)-cleavable, selectively activating the fluorescence at MMP-positive tumor microenvironments. They systemically injected the NPs into MMP2-positive HT-29 tumor-bearing mice. At 24 hours postinjection, the NPs showed contrast effects at the tumor site with both CT and NIRF imaging. ${ }^{85}$

Zhou et al showed optical and CT multimodality NPs using folic acid and gold NPs that were incorporated by silica. The NPs were evaluated with gastric cancer models. The prepared NPs showed preferred targeting ability to folate receptor (FR) (+) human gastric mucosal cancer cell (MGC)-803, while few were taken up in FR(-) normal gastric epithelial cell (GES-1). ${ }^{86}$ This approach could be useful for diagnosis by $\mathrm{CT}$ and surgical removal by fluorescent imaging.

Sun et al demonstrated upconversion nanophosphors $\left(\mathrm{NaLuF}_{4}: \mathrm{Yb}, \mathrm{Tm}\right)$ for upconversion luminescence imaging and $\mathrm{CT}$ multimodality imaging. $\mathrm{NaLuF}_{4}$-based upconversion material can be visualized even under ambient light. This function can provide a more convenient surgical environment. Also due to the heavy element lutetium, the nanophosphors can be used as a CT agent. The nanophosphors visualized the dual-modality imaging of lymphatic vessels. ${ }^{87}$

Recently, some research groups have demonstrated trimodality imaging. Trimodality imaging agents can provide even more information than single-modality or dual-modality imaging. Various combinations can be designed for better imaging information. Hwang et al demonstrated trimodality NPs for radionuclide, MR, and fluorescence imaging. They made a cobalt-ferrite NP surrounded by rhodamine within a silica shell, which was conjugated with nucleolin-targeting aptamer. Nucleolin is a cell-membrane protein highly expressed in cancer. The NPs were bounded with chelating agents and further labeled with ${ }^{67} \mathrm{Ga}$ citrate for radionuclide imaging (MFR-AS1411). MFR-AS1411 NPs were injected into the mice, and in vivo tumor images by radionuclide and MR imaging and ex-vivo images by optical imaging were taken. ${ }^{88}$ Xie et al also demonstrated PET-NIRF-MRI trimodality NPs for U87MG human glioblastoma tumor imaging. They utilized dopamine to modify the surface of IO NPs, and the IO NPs were easily encapsulated by human serum albumin (HSA), which is used clinically as a drug carrier. The HSAcovered IO NPs were further labeled with ${ }^{64} \mathrm{Cu}$-DOTA and Cy5.5 for PET and NIRF imaging (HSA-IONPs). The HSAIONPs were evaluated in NIRF/PET/MRI (Figure 7). ${ }^{89}$

With MR, PET, CT, or optical imaging, another imaging modality can usually be combined with them. For example, US can also be used for multimodality imaging. A big advantage of US is its high safety, so it is currently used for pregnant women or infants. However, it has some limitations, such as penetration depth (eg, several centimeters), bad sensitivity, and working poorly in air-containing organs. ${ }^{4}$ However the image quality of US can be enhanced by combination with another imaging modality. John et al reported the micron-sized particles for cancer imaging in MRI, magnetomotive optical coherence tomography, and US. Their particles consisted of protein-shell microspheres that were filled with iron oxide NPs in oil, and also the microspheres were functionalized with RGD peptides. ${ }^{90} \mathrm{Kim}$ et al demonstrated micron-sized capsules that contained gold, IO, and islet cells for immunoprotection and CT-MR-US trimodality imaging. They injected the capsules into the mouse abdomen and evaluated the contrast effects in the three modalities. ${ }^{91}$

Lee et al also demonstrated a trimodality imaging agent for upconversion luminescence, MR, and PET imaging. For upconversion nanophosphors (UCNPs), they reported $\mathrm{NaYF}_{4}: \mathrm{Yb}^{31} / \mathrm{Er}^{31}$ which was developed for in vivo optical imaging using a 980-nm laser. They modified UCNPs for luminescence, MR, and PET imaging for which they replaced $\mathrm{Y}$ with $\mathrm{Gd}$ in $\mathrm{NaYF}_{4}: \mathrm{Yb}^{31} / \mathrm{Er}^{31}$ and also coated dimeric cyclic RGDyk peptides and MeO-PEG-NH ${ }_{2}$. The tyrosine residues of the peptide were used to label with ${ }^{124} \mathrm{I}$. The UCNPs were evaluated in the three imaging modalities, demonstrating the localized UCNPs at the U87MG tumors. ${ }^{92}$ 

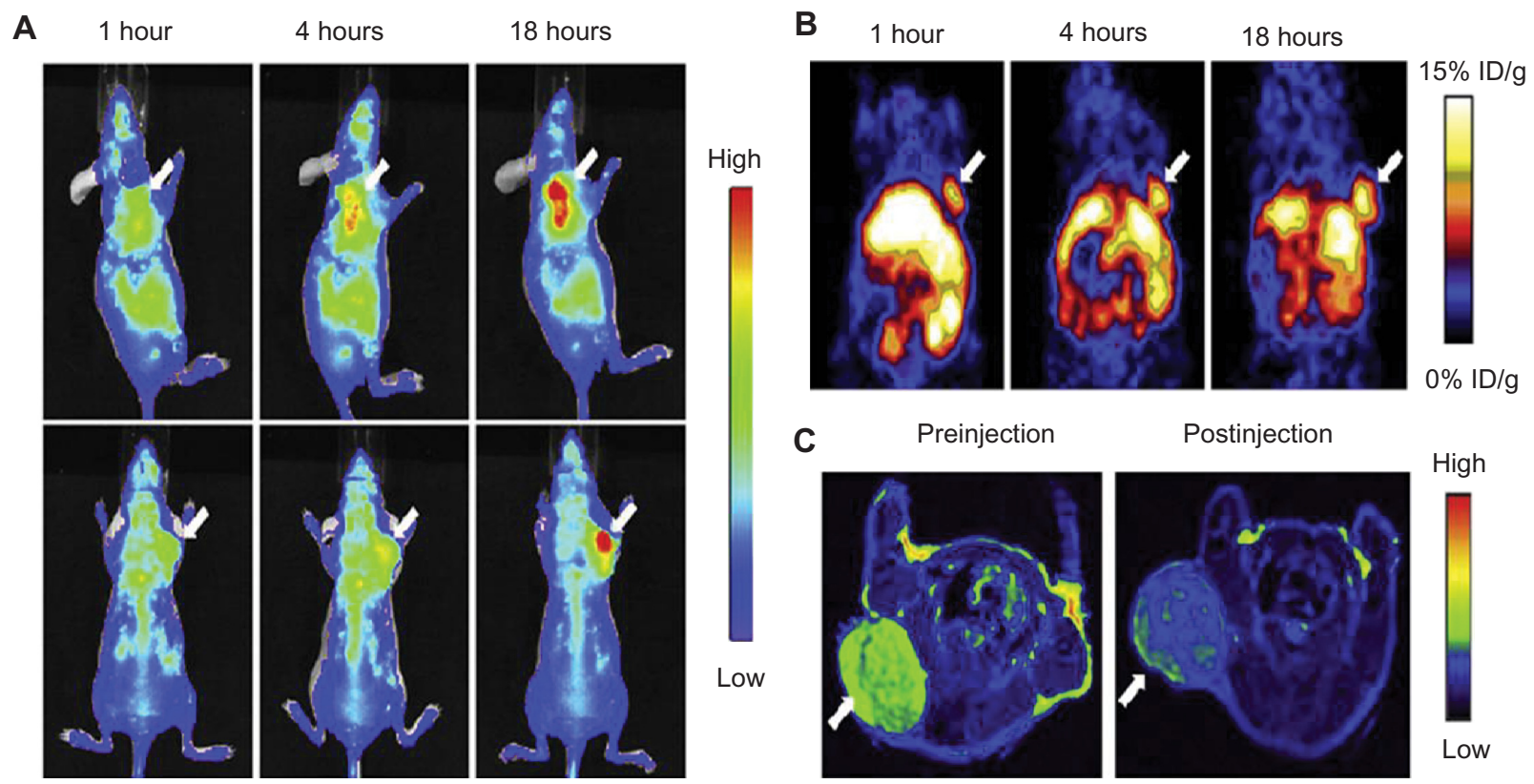

C

\begin{abstract}
Preinjection
\end{abstract}

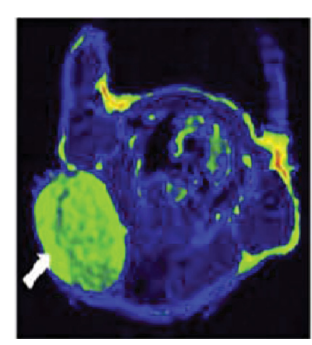

Postinjection

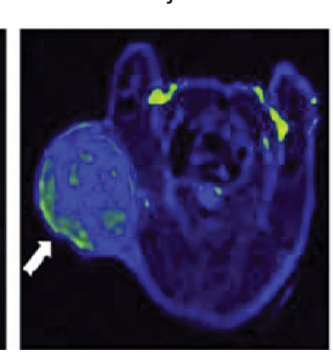

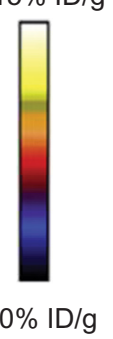

High

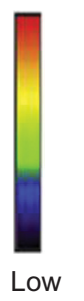

Figure 7 (A-C) In vivo optical-positron emission tomography (PET)-magnetic resonance (MR) trimodality imaging by human serum albumin iron oxide nanoparticles. Images of I, 4, and 18 hours postinjection. (A) In vivo near-infrared fluorescent images of mice; (B) in vivo PET images of mice; (C) in vivo MR images of mice, I8 hours postinjection; white arrows indicate xenograft U87MG tumors.

Reprinted from Xie J, Chen K, Huang J, et al. PET/NIRF/MRI triple functional iron oxide nanoparticles. Biomaterials. 20I0;3I(II):30I6-3022. Copyright @ 20I0, with permission from Elsevier. ${ }^{88}$

In summary, trimodality imaging can provide more information than either single- or dual-modality imaging. However, the performance of dual- or trimodal NPs cannot always have better than a single modality imaging agent in terms of stability, targeting specificity, toxicity, or biocompatibility in the body. Boerman and Oyen pointed out the potential risk inherent in the development of multimodality probes by using the metaphor "... an amphibious car which is not as fast as a sports car, and it is not good as a speed boat in the water." ${ }^{93}$ In the design of multimodality imaging agents, potential problems with imaging quality must be considered. The results of combining different modalities are not always predictable.

In this paper, we have reviewed basic principles, contrast agents, and recent studies of multimodality imaging agents. These approaches can be very useful to minimize errors from a single imaging modality in human diagnosis, and also can support image-guided surgery systems to delineate cancer cells from normal cells, minimizing side effects from invasive surgical procedures. However, for human application, various factors such as toxicity or biocompatibility must be considered broadly for long-term effects.

\section{Summary}

Use of multiple imaging modes can allow extension of imaging across wide dynamic ranges of size resolution and penetration depth from deep-body CT, MR, and PET imaging, with size resolutions of about $1 \mathrm{~mm}$ to shallow penetration depths of at best a few hundred microns or a few millimeters by fluorescence imaging, but with more sensitive size resolutions to single-cell and or even subcellular resolution. By using these modalities in combination, one can detect diseased cells deep within the body, determine their exact location for subsequent stereotactic surgery, and with fluorescence-guided surgery and magnified imaging detect diseased cells such as micrometastases at micron-level resolution.

\section{Acknowledgments}

This work was supported by the KIST-Purdue GRL (Global Research Laboratory) Collaboration ("Molecular imaging and nanomedicine for theragnosis using nanobiomaterials" [grant 202979]) and the Christopher Columbus Foundation.

\section{Disclosure}

The authors report no conflicts of interest in this work.

\section{References}

1. van Dam GM, Themelis G, Crane LM, et al. Intraoperative tumor-specific fluorescence imaging in ovarian cancer by folate receptor- $\alpha$ targeting: first in-human results. Nat Med. 2011;17(10):1315-1319.

2. Leary JF. Nanotechnology: what is it and why is small so big? Can J Ophthalmol. 2010;45(5):449-456.

3. Weissleder R, Pittet MJ. Imaging in the era of molecular oncology. Nature. 2008;452(7187):580-589. 
4. Hahn M, Singh A, Sharma P, Brown S, Moudgil B. Nanoparticles as contrast agents for in vivo bioimaging: current status and future perspectives. Anal Bioanal Chem. 2011;399(1):3-27.

5. Cheon J, Lee JH. Synergistically integrated nanoparticles as multimodal probes for nanobiotechnology. Acc Chem Res. 2008;41(12): 1630-1640.

6. Kim JH, Park K, Nam HY, Lee S, Kim K, Kwon IC. Polymers for bioimaging. Prog Polym Sci. 2007;32(8-9):1031-1053.

7. Caravan P. Strategies for increasing the sensitivity of gadolinium based MRI contrast agents. Chem Soc Rev. 2006;35(6):512-523.

8. Abujudeh HH, Kaewlai R, Kagan A, et al. Nephrogenic systemic fibrosis after gadopentetate dimeglumine exposure: case series of 36 patients. Radiology. 2009 2009;253(1):81-89.

9. Thomsen H. Gadolinium-based contrast media may be nephrotoxic even at approved doses. Eur Radiol. 2004;14(9):1654-1656.

10. Na HB, Song IC, Hyeon T. Inorganic nanoparticles for MRI contrast agents. Adv Mater. 2009;21(21):2133-2148.

11. Aryal S, Key J, Stigliano C, Ananta JS, Zhong M, Decuzzi P. Engineered magnetic hybrid nanoparticles with enhanced relaxivity for tumor imaging. Biomaterials. 2013;34(31):7725-7732.

12. Park J, An K, Hwang Y, et al. Ultra-large-scale syntheses of monodisperse nanocrystals. Nat Mater. 2004;3(12):891-895.

13. Lee JH, Jang JT, Choi JS, et al. Exchange-coupled magnetic nanoparticles for efficient heat induction. Nat Nanotechnol. 2011;6(7):418-422.

14. Duguet E, Vasseur S, Mornet S, Devoisselle JM. Magnetic nanoparticles and their applications in medicine. Nanomedicine (Lond). 2006;1(2):157-168.

15. Cunningham CH, Arai T, Yang PC, McConnell MV, Pauly JM, Conolly SM. Positive contrast magnetic resonance imaging of cells labeled with magnetic nanoparticles. Magn Reson Med. 2005;53(5):999-1005.

16. Kim YB, Bae KH, Yoo SS, Park TG, Park H. Positive contrast visualization for cellular magnetic resonance imaging using susceptibility-weighted echo-time encoding. Magn Reson Imaging. 2009;27(5):601-610.

17. Zhu H, Jones CK, van Zijl PCM, Barker PB, Zhou J. Fast 3D chemical exchange saturation transfer (CEST) imaging of the human brain. Magn Reson Med. 2010;64(3):638-644.

18. Day S, Kettunen M, Gallagher F, et al. Detecting tumor response to treatment using hyperpolarized $13 \mathrm{C}$ magnetic resonance imaging and spectroscopy. Nat Med. 2007;13(11):1382-1387.

19. Gallagher F, Kettunen M, Day S, et al. Magnetic resonance imaging of $\mathrm{pH}$ in vivo using hyperpolarized 13C-labelled bicarbonate. Nature. 2008;453(7197):940-943.

20. Lee JH, Huh YM, Jun YW, et al. Artificially engineered magnetic nanoparticles for ultra-sensitive molecular imaging. Nat Med. 2007;13(1):95-99.

21. Lee N, Kim H, Choi SH, et al. Magnetosome-like ferrimagnetic iron oxide nanocubes for highly sensitive MRI of single cells and transplanted pancreatic islets. Proc Natl Acad Sci U S A. 2011;108(7):2662-2667.

22. Lee N, Choi Y, Lee Y, et al. Water-dispersible ferrimagnetic iron oxide nanocubes with extremely high $\mathrm{r}_{2}$ relaxivity for highly sensitive in vivo MRI of tumors. Nano Lett. 2012;12(6):3127-3131.

23. Key J, Dhawan D, Knapp DW, et al. Multimodal in vivo MRI and NIRF imaging of bladder tumor using peptide conjugated glycol chitosan nanoparticles. Proc SPIE. 2012;8225.

24. Brasch RC. Rationale and applications for macromolecular Gd-based contrast agents. Magn Reson Med. 1991;22(2):282-287.

25. Adam G, Neuerburg J, Spuntrup E, Mühler A, Scherer K, Günther RW. Gd-DTPA-cascade-polymer: potential blood pool contrast agent for MR imaging. J Magn Reson Imaging. 1994;4(3):462-466.

26. Roberts HC, Saeed M, Roberts TP, et al. Comparison of albumin(Gd-DTPA) 30 and Gd-DTPA-24-cascade-polymer for measurements of normal and abnormal microvascular permeability. J Magn Reson Imaging. 1997;7(2):331-338.

27. Orang-Khadivi K, Pierce BL, Ollom CM, Floyd LJ, Siegle RL, Williams RF. New magnetic resonance imaging techniques for the detection of breast cancer. Breast Cancer Res Treat. 1994;32(1):119-135.
28. Wiener EC, Brechbiel MW, Brothers H, et al. Dendrimer-based metal chelates: a new class of magnetic resonance imaging contrast agents. Magn Reson Med. 1994;31(1):1-8.

29. Reimer P, Balzer T. Ferucarbotran (Resovist): a new clinically approved RES-specific contrast agent for contrast-enhanced MRI of the liver: properties, clinical development, and applications. Eur Radiol. 2003;13(6):1266-1276.

30. Jung CW, Jacobs P. Physical and chemical properties of superparamagnetic iron oxide MR contrast agents: ferumoxides, ferumoxtran, ferumoxsil. Magn Reson Imaging. 1995;13(5):661-674.

31. Reimer P, Tombach B. Hepatic MRI with SPIO: detection and characterization of focal liver lesions. Eur Radiol. 1998;8(7):1198-1204.

32. Bulte JW, Brooks RA, Moskowitz BM, Bryant LH, Frank JA. Relaxometry and magnetometry of the MR contrast agent MION-46L. Magn Reson Med. 1999;42(2):379-384.

33. Bogdanov AA Jr, Martin C, Weissleder R, Brady TJ. Trapping of dextran-coated colloids in liposomes by transient binding to aminophospholipid: preparation of ferrosomes. Biochim Biophys Acta. 1994;1193(1):212-218.

34. Bulte JWM, Md C, Despres D, Frank JA. Preparation, relaxometry, and biokinetics of PEGylated magnetoliposomes as MR contrast agent. J Magn Magn Mater. 1999;194(1-3):204-209.

35. Brenner DJ, Elliston CD, Hall EJ, Berdon WE. Estimated risks of radiation-induced fatal cancer from pediatric CT. AJR Am J Roentgenol. 2001;176(2):289-296.

36. Seltzer SM, Berger MJ. Bremsstrahlung spectra from electron interactions with screened atomic nuclei and orbital electrons. $\mathrm{Nucl}$ Instrum Methods Phys Res B. 1985;12(1):95-134.

37. Pietsch H. CT contrast agents. In: Kiessling F, Pichler BJ, editors. Heidelberg: Springer; 2011:141-149.

38. Kong WH, Lee WJ, Cui ZY, et al. Nanoparticulate carrier containing water-insoluble iodinated oil as a multifunctional contrast agent for computed tomography imaging. Biomaterials. 2007;28(36):5555-5561.

39. Elrod DB, Partha R, Danila D, Casscells SW, Conyers JL. An iodinated liposomal computed tomographic contrast agent prepared from a diiodophosphatidylcholine lipid. Nanomedicine. 2009;5(1):42-45.

40. Skajaa T, Cormode DP, Falk E, Mulder WJM, Fisher EA, Fayad ZA. Highdensity lipoprotein-based contrast agents for multimodal imaging of atherosclerosis. Arterioscler Thromb Vasc Biol. 2010;30(2): 169-176.

41. Aviv H, Bartling S, Kieslling F, Margel S. Radiopaque iodinated copolymeric nanoparticles for X-ray imaging applications. Biomaterials. 2009;30(29):5610-5616.

42. Rabin O, Manuel Perez J, Grimm J, Wojtkiewicz G, Weissleder R. An $\mathrm{X}$-ray computed tomography imaging agent based on long-circulating bismuth sulphide nanoparticles. Nat Mater. 2006;5(2):118-122.

43. Kim D, Yu MK, Lee TS, Park JJ, Jeong YY, Jon S. Amphiphilic polymer-coated hybrid nanoparticles as CT/MRI dual contrast agents. Nanotechnology. 2011;22(15):155101.

44. Kim D, Park S, Lee JH, Jeong YY, Jon S. Antibiofouling polymercoated gold nanoparticles as a contrast agent for in vivo X-ray computed tomography imaging. J Am Chem Soc. 2007;129(24):7661-7665.

45. Jackson PA, Rahman WN, Wong CJ, Ackerly T, Geso M. Potential dependent superiority of gold nanoparticles in comparison to iodinated contrast agents. Eur J Radiol. 2010;75(1):104-109.

46. Popovtzer R, Agrawal A, Kotov NA, et al. Targeted gold nanoparticles enable molecular CT imaging of cancer. Nano Lett. 2008;8(12): 4593-4596.

47. Cai QY, Kim SH, Choi KS, et al. Colloidal gold nanoparticles as a blood-pool contrast agent for X-ray computed tomography in mice. Invest Radiol. 2007;42(12):797-806.

48. Massoud TF, Gambhir SS. Molecular imaging in living subjects: seeing fundamental biological processes in a new light. Genes Dev. 2003;17(5):545-580.

49. Rosenthal MS, Cullom J, Hawkins W, Moore SC, Tsui BMW, Yester M. Quantitative SPECT imaging: a review and recommendations by the Focus Committee of the Society of Nuclear Medicine Computer and Instrumentation Council. J Nucl Med. 1995;36(8):1489-1513. 
50. Strijckmans K. The isochronous cyclotron: principles and recent developments. Comput Med Imaging Graph. 2001;25(2):69-78.

51. YeY, Chen X. Integrin targeting for tumor optical imaging. Theranostics. 2011;1:102-126.

52. Kim K, Kim JH, Park H, et al. Tumor-homing multifunctional nanoparticles for cancer theragnosis: simultaneous diagnosis, drug delivery, and therapeutic monitoring. J Control Release. 2010;146(2):219-227.

53. Lin TY, Zhang H, Wang S, et al. Targeting canine bladder transitional cell carcinoma with a human bladder cancer-specific ligand. $\mathrm{Mol}$ Cancer. 2011;10(1):9.

54. Licha K, Olbrich C. Optical imaging in drug discovery and diagnostic applications. Adv Drug Deliv Rev. 2005;57(8):1087-1108.

55. Ntziachristos V, Chance B. Breast imaging technology: probing physiology and molecular function using optical imaging: applications to breast cancer. Breast Cancer Res. 2000;3(1):41-46.

56. Michalet X, Pinaud FF, Bentolila LA, et al. Quantum dots for live cells, in vivo imaging, and diagnostics. Science. 2005;307(5709):538-544.

57. Janczewski D, Zhang Y, Das GK, et al. Bimodal magnetic-fluorescent probes for bioimaging. Microsc Res Tech. 2011;74(7):563-576.

58. Wang F, Banerjee D, Liu Y, Chen X, Liu X. Upconversion nanoparticles in biological labeling, imaging, and therapy. Analyst. 2010;135(8):1839-1854.

59. Yu XF, Chen LD, Li M, et al. Highly efficient fluorescence of $\mathrm{NdF}_{3} / \mathrm{SiO}_{2}$ core/shell nanoparticles and the applications for in vivo NIR detection. Adv Mater. 2008;20(21):4118-4123.

60. Wang L, Zhang Y, Zhu Y. One-pot synthesis and strong near-infrared upconversion luminescence of poly(acrylic acid)-functionalized $\mathrm{YF}_{3}: \mathrm{Yb}^{3+} / \mathrm{Er}^{3+}$ nanocrystals. Nano Res. 2010;3(5):317-325.

61. Melancon MP, Wang Y, Wen X, et al. Development of a macromolecular dual-modality MR-optical imaging for sentinel lymph node mapping. Invest Radiol. 2007;42(8):569-578.

62. Knapp DW, Adams LG, DeGrand AM, et al. Sentinel lymph node mapping of invasive urinary bladder cancer in animal models using invisible light. Eur Urol. 2007;52(6):1700-1709.

63. Swierczewska M, Lee S, Chen X. Inorganic nanoparticles for multimodal molecular imaging. Mol Imaging. 2011;10(1):3-16.

64. Lee DE, Koo H, Sun IC, Ryu JH, Kim K, Kwon IC. Multifunctional nanoparticles for multimodal imaging and theragnosis. Chem Soc Rev. 2012;41(7):2656-2672.

65. Louie A. Multimodality imaging probes: design and challenges. Chem Rev. 2010;110(5):3146-3195.

66. Pichler BJ, Judenhofer MS, Pfannenberg C. Multimodal imaging approaches: PET/CT and PET/MRI. Handb Exp Pharmacol. 2008, (185 Pt 1):109-132.

67. Judenhofer MS, Wehrl HF, Newport DF, et al. Simultaneous PET-MRI: a new approach for functional and morphological imaging. Nat Med. 2008;14(4):459-465.

68. Nam T, Park S, Lee SY, et al. Tumor targeting chitosan nanoparticles for dual-modality optical/MR cancer imaging. Bioconjug Chem 2010;21(4):578-582.

69. Nguyen QT, Olson ES, Aguilera TA, et al. Surgery with molecular fluorescence imaging using activatable cell-penetrating peptides decreases residual cancer and improves survival. Proc Natl Acad Sci U S A. 2010;107(9):4317-4322.

70. Key J, Kim K, Dhawan D, et al. Dual-modality in vivo imaging for MRI detection of tumors and NIRF-guided surgery using multi-component nanoparticles. Vol: Proc SPIE. 2011;79087:90805.

71. Key J, Cooper C, Kim A, et al. In vivo NIRF and MR dual-modality imaging using glycol chitosan nanoparticles. J Control Release. 2012;163(2):249-255.

72. Yu Y, Sun D. Superparamagnetic iron oxide nanoparticle theranostics for multimodality tumor imaging, gene delivery, targeted drug and prodrug delivery. Expert Rev Clin Pharmacol. 2010;3 (1):117-130.

73. Maeda $\mathrm{H}$. Tumor-Selective delivery of macromolecular drugs via the EPR effect: background and future prospects. Bioconjug Chem. 2010;21(5):797-802.
74. Chen K, Xie J, Xu H, et al. Triblock copolymer coated iron oxide nanoparticle conjugate for tumor integrin targeting. Biomaterials. 2009;30(36):6912-6919.

75. Tan YF, Chandrasekharan P, Maity D, et al. Multimodal tumor imaging by iron oxides and quantum dots formulated in poly (lactic acid)-dalpha-tocopheryl polyethylene glycol 1000 succinate nanoparticles. Biomaterials. 2011;32(11):2969-2978.

76. Zhou J, Sun Y, Du X, Xiong L, Hu H, Li F. Dual-modality in vivo imaging using rare-earth nanocrystals with near-infrared to near-infrared (NIR-to-NIR) upconversion luminescence and magnetic resonance properties. Biomaterials. 2010;31(12):3287-95.

77. Tian QW, Hu TQ, Zhu YH, et al. Sub-10 nm Fe $\mathrm{O}_{4} @ \mathrm{Cu}_{2-\mathrm{x}} \mathrm{S}$ core-shell nanoparticles for dual-modal imaging and photothermal therapy. $J \mathrm{Am}$ Chem Soc. 2013;135(23):8571-8577.

78. Huang Y, Hu L, Zhang T, et al. $\mathrm{Mn}_{3}\left[\mathrm{Co}(\mathrm{CN})_{6}\right]_{2} @ \mathrm{SiO}_{2}$ core-shell nanocubes: novel bimodal contrast agents for MRI and optical imaging. Sci Rep. 2013;3:2647.

79. Yang X, Hong H, Grailer JJ, et al. cRGD-functionalized, DOXconjugated, and ${ }^{64} \mathrm{Cu}$-labeled superparamagnetic iron oxide nanoparticles for targeted anticancer drug delivery and PET/MR imaging. Biomaterials. 2011;32(17):4151-4160.

80. Torres Martin de Rosales R, Tavaré R, Paul RL, et al. Synthesis of ${ }^{64} \mathrm{Cu}$ (II)-bis(dithiocarbamatebisphosphonate) and its conjugation with superparamagnetic iron oxide nanoparticles: in vivo evaluation as dual-modality PET-MRI agent. Angew Chem Int Ed Engl. 2011;50(24):5509-5513.

81. Torres Martin de Rosales R, Tavaré R, Glaria A, Varma G, Protti A, Blower PJ. $\left({ }^{99} \mathrm{~m}\right) \mathrm{Tc}$-bisphosphonate-iron oxide nanoparticle conjugates for dual-modality biomedical imaging. Bioconjug Chem. 2011;22(3):455-465.

82. Choi JS, Park JC, Nah H, et al. A hybrid nanoparticle probe for dualmodality positron emission tomography and magnetic resonance imaging. Angew Chem Int Ed Engl. 2008;47(33):6259-6262.

83. Uppal R, Catana C, Ay I, Benner T, Sorensen AG, Caravan P. Bimodal thrombus imaging: simultaneous PET/MR imaging with a fibrintargeted dual PET/MR probe - feasibility study in rat model. Radiology. 2011;258(3):812-820.

84. Zhu H, Zhao J, Lin X, Hong Y, Li C, Yang Z. Design, synthesis and evaluation of dual-modality glyco-nanoparticles for tumor imaging. Molecules. 2013;18(6):6425-6438.

85. Sun IC, Eun DK, Koo H, et al. Tumor-targeting gold particles for dual computed tomography/optical cancer imaging. Angew Chem Int Ed Eng. 2011;123(40):9520-9523.

86. Zhou Z, Zhang C, Qian Q, et al. Folic acid-conjugated silica capped gold nanoclusters for targeted fluorescence/X-ray computed tomography imaging. J Nanobiotechnology. 2013;11(1):17.

87. Sun Y, Peng J, Feng W, Li F. Upconversion nanophosphors $\mathrm{NaluF}_{4}: \mathrm{Yb}, \mathrm{Tm}$ for lymphatic imaging in vivo by real-time upconversion luminescence imaging under ambient light and high-resolution X-ray CT. Theranostics. 2013;3(5):346-353.

88. Hwang DW, Ko HY, Lee JH, et al. A nucleolin-targeted multimodal nanoparticle imaging probe for tracking cancer cells using an aptamer. J Nucl Med. 2010;51(1):98-105.

89. Xie J, Chen K, Huang J, et al. PET/NIRF/MRI triple functional iron oxide nanoparticles. Biomaterials. 2010;31(11):3016-3022.

90. John R, Nguyen F, Kolbeck K, et al. Targeted multifunctional multimodal protein-shell microspheres as cancer imaging contrast agents. Mol Imaging Biol. 2012;14(1):17-24.

91. Kim J, Arifin DR, Muja N, et al. Multifunctional capsule-in-capsules for immunoprotection and trimodal imaging. Angew Chem Int Ed Engl. 2011;50(10):2317-2321.

92. Lee J, Lee TS, Ryu J, et al. RGD peptide-conjugated multimodal $\mathrm{NaGdF}_{4}: \mathrm{Yb}^{3+} / \mathrm{Er}^{3+}$ nanophosphors for upconversion luminescence, $\mathrm{MR}$, and PET imaging of tumor angiogenesis. J Nucl Med 2013;54(1):96-103.

93. Boerman OC, Oyen WJ. Multimodality probes: amphibian cars for molecular imaging. J Nucl Med. 2008;49(8):1213-1214. 


\section{Publish your work in this journal}

The International Journal of Nanomedicine is an international, peerreviewed journal focusing on the application of nanotechnology in diagnostics, therapeutics, and drug delivery systems throughout the biomedical field. This journal is indexed on PubMed Central, MedLine, CAS, SciSearch $\AA$, Current Contents ${ }^{\circledR} /$ Clinical Medicine,

Journal Citation Reports/Science Edition, EMBase, Scopus and the Elsevier Bibliographic databases. The manuscript management system is completely online and includes a very quick and fair peer-review system, which is all easy to use. Visit http://www.dovepress.com/ testimonials.php to read real quotes from published authors.

Submit your manuscript here: http://www.dovepress.com/international-journal-of-nanomedicine-journal 